\title{
Decarbonizing strategies of the retail sector following the Paris Agreement
}

\author{
Ferreira Ana ${ }^{\mathrm{a}, *}$, Manuel Duarte Pinheiro ${ }^{\mathrm{a}}$, Jorge de Brito ${ }^{\mathrm{a}}$, Ricardo Mateus ${ }^{\mathrm{b}}$ \\ ${ }^{a}$ CERIS, Instituto Superior Técnico, Universidade de Lisboa, Av. Rovisco Pais, 1, 1049-001, Lisboa, Portugal \\ ${ }^{\mathrm{b}}$ CTAC, University of Minho, Department of Civil Engineering, Campus de Azurém, 4800-058, Guimarães, Portugal
}

\section{A R T I C L E I N F O}

\section{Keywords:}

Retail

Corporate social responsibility

Energy-related building solutions

Sustainability

Paris Agreement

\begin{abstract}
A B S T R A C T
The retail industry is one of the top 10 most carbon-intensive sectors. This paper is original in addressing what has changed in corporate retail with the Paris Agreement, accessing trends to decarbonize the sector. A qualitative comparison was performed regarding the policy, strategy and energy-related building solutions of the top 27 global retailers, ranked according to their revenue, regarding the reporting periods of 2014-2015 and 2016-2017. For each retailer, data were searched on retailers' sustainability reports was organized in different tables according to the variables policy, strategy and energy-related building practice. A comparison analysis was carried out, in order to identify differentiating decarbonizing measures.

Corporate governance is increasingly relevant to manage climate change issues. Strategies to decarbonize the retail sector include establishing ambitious energy goals, invest in sustainability of supply chain with more efficient logistics and in greener retail operations, with buildings designed and managed under a life-cycle perspective (energy-efficiency, renewable energy and natural refrigerants). Retailers are progressively aligning their energy targets to those of the Paris Agreement and converging in business principles and reporting standards. With forthcoming regulation on GHG emissions, retailers could benefit from a business case on lowcarbon opportunities and financial incentives to accelerate low-carbon transition investments.
\end{abstract}

\section{Introduction}

The retail industry is one of the top 10 most carbon-intensive business sectors (Jackson and Apostolakou, 2010; United Nations CLimate Change, 2018; Reinvent Decarbonisation, 2017). In fact, retail stores have one of the highest energy intensities - 500 to $1.000 \mathrm{kWh} /$ $\mathrm{m}^{2} / \mathrm{y}$ (Schönberger et al., 2013). In addition, retailers' environmental footprint is quite high in terms of direct GHG emissions and even higher in terms of indirect emissions - a factor of 7 for its supply chain and a factor of 3 for its products' life-cycle (ENDS Carbon - University of Edinburgh Business School, 2009).

The retail sector controls and acts as the gatekeeper for goods and consumer services and, as such, it can influence behaviour and consumption patterns (The Conservation Foundation of Greater Toronto, 2006). Because of its broad reach, the retail sector has the potential to affect society in a way that not many other industries can. Corporately, retailers can define environmentally oriented policies internally and for suppliers and at the point-of-sale they can showcase sustainable built stores and educate consumers. The retail sector is also in a key position in the construction industry, as it can influence the supply stream of materials and technologies used in this sector (U.S. Department of
Energy, 2008). As retail is a highly concentrated industry in terms of ownership and sales (The Conservation Foundation of Greater Toronto, 2006), there is an easier best practice communication across all players in the industry: lessons learned can easily be transferred across the sector.

Parallel to corporate social responsibility (CSR), international regulation is urging retailers into energy and carbon efficiency, namely due to the Paris Agreement (United Nations, 2015a), the Montreal Protocol (United Nations Environment, 2017), or the Energy Performance of Buildings Directive (EPBD) (European ParliamentEuropean Council, 2014). In fact, according to the EPBD, commercial buildings need to become 70\%-80\% more energy-efficient and all new buildings must be nearly-zero energy buildings (nZEBs) by 2020 . With nearly 20 years after the Rio Declaration on Environment and Development (United Nations, 1992), the Paris Agreement has called upon all societal actors to fight climate change (United Nations, 2015a) (United Nations Environment, 2017). Retail can play a key part in this pledge, leading the way to decrease energy consumption and GHG emissions. Indeed, according to Retail Industry Leaders Association (RILA), retailers' overall environmental impact is recognized by them as a substantial problem requiring a more comprehensive CSR sustainability-driven

\footnotetext{
* Corresponding author. Instituto Superior Técnico, Avenida Rovisco Pais, 1, 1049 - 001 Lisboa, Portugal.

E-mail addresses: anaferreiraleonardo@tecnico.ulisboa.pt (A. Ferreira), manuel.pinheiro@tecnico.ulisboa.pt (M.D. Pinheiro), jb@civil.ist.utl.pt (J. de Brito), ricardomateus@civil.uminho.pt (R. Mateus).
} 
management approach (RILA - Retail Industry Leaders Association, 2017). Hence, retail corporations have attempted to manage their environmental impacts by implementing effective CSR policies, strategies (Pulker et al., 2018) and sustainable building practices.

On that matter, Garriga and Melé (2013) classified the most relevant CSR theories as instrumental, political, integrative and value-based. Most current CSR theories are focused on a combination of producing long-term profits, using business power in a responsible way, integrating social demands and contributing to society by doing what is ethically correct (Garriga and Melé, 2013). Under the ethical CSR theories, the sustainable development approach is popular in retail. Sustainable development seeks to meet present needs without compromising the ability of the future generations to meet their own needs (United Nations, 2015c). This means integrating social, environmental, and economic considerations in long-term business decisions (Garriga and Melé, 2013). In addition, Marrewijk (2003) proposed corporate sustainability as a voluntary custom-made process, integrating different ambition levels of corporate sustainability (Marrewijk, 2003), which this paper will also highlight. Other studies identified relevant practices in CSR and governance that can be applicable to retail (Lozano, 2015; Baker et al., 2012; Cowanet al., 2010; Reilly and Hynan, 2014; Thijssens et al., 2016; Wartick and Cochran, 1985; Sullivan and Gouldson, 2013; Hart, 1995; Smith and Higgins, 2000; Donaldson and Dunfee, 1994; Davis, 1960).

Corporate governance has also evolved over time, from protecting the interests of shareholders to including a longer-term and more socially and environmentally responsible business approach (Fenwick et al., 2019). On this matter, Keay and Iqbal (2018) investigated the attitude of companies towards sustainability and how are they integrating sustainability in corporate governance (Keay and Iqbal, 2018). In addition, Dupuis and Schweizer (2019) examined the conditions under which corporate actors could become leaders in climate governance (Dupuis and Schweizer, 2019). Other studies assessed corporate barriers and drivers for energy and carbon efficiency (Gliedt and Hoicka, 2015; Dixon-O Mara and Ryan, 2018).

Empirical studies have shown mixed results regarding the effect of environmental performance on environmental disclosure communicated by CSR (Al-Tuwaijri et al., 2004; Clarkson et al., 2011; Yu, 2015). Jackson and Apostolakou (2010) assessed the link between CSR practices and improved financial performance, concluding that firms in high-impact sectors - such as retail - have higher CSR scores than firms in other sectors, particularly in the environmental dimension of CSR (Jackson and Apostolakou, 2010). Furthermore, according to Parguel et al. (2011), Kim and Lyon (2015) and Hahn and Luelfs (2014), voluntary standards - such as those adopted by retail - tend to signal positive environmental performance and deter companies from greenwashing (Parguel et al., 2011)- (Hahn and Luelfs, 2014). Moreover, in a novel study intended to ascertain the reliability level of carbon, Giannarakis et al. (2017) suggested a positive relationship between voluntary carbon disclosure and environmental performance (Giannarakis et al., 2017). Likewise, Sullivan \& Gouldson (2013, 2016) examined retail corporate action on climate change, regarding the period 2000-2010, as well as the rates of improvement in English and American retailers' energy consumption and GHG emissions. Other studies assessed energy and carbon efficiency in retail buildings (DixonO'Mara and Ryan, 2018) (Christina et al., 2015; Ji et al., 2017; Lukić et al., 2018; Bălan, 2010) and studied policy and strategy challenges to address climate change regarding the building stock (Sebi et al., 2019; Carballo-Penela and Castromán-Diz, 2015).

However, knowledge on how retailers are recently addressing climate change in the aftermath of the Paris Agreement remains unexplored, namely in terms of policies, strategies and energy-related building solutions that can foster the decarbonization of the retail sector. Nonetheless, knowledge about these issues is essential in the transition to a low-carbon economy not only in the retail sector but in other industries as well. The following paragraphs define the scope of policy, strategy and energy-related building practice for the present study.

Policies are formal rules of an organization that help standardize decision-making. Policy can be defined as a plan of what to do that has been agreed to officially by a business organization or a government. The political context for retailer's climate change action has been recently set mainly by the Paris Agreement. The Paris Agreement, a new legally-binding framework for an internationally coordinated effort to tackle climate change ratified by 175 member-states, intended to strengthen the global response to the threat of climate change, by: a) holding the increase in the global average temperature to well below $2{ }^{\circ} \mathrm{C}$ above pre-industrial levels and pursuing efforts to limit the temperature increase to $1.5^{\circ} \mathrm{C}$ above pre-industrial levels, recognizing that this would significantly reduce the risks and impacts of climate change; and $b$ ) increasing the ability to adapt to the adverse impacts of climate change and foster climate resilience and low greenhouse gas emissions development, in a manner that does not threaten food production (United Nations, 2015a). In addition, Parties aimed at reaching global peaking of GHG emissions as soon as possible - the point when global emissions reach a maximum level and then start to decline - and to undertake reductions thereafter, so as to achieve a balance between emissions by sources and removals in the second half of this century (thereby implementing the concept of zero net emissions). Furthermore, the Agreement was based on the principle of common but differentiated responsibilities and capabilities, with developed memberstates taking the lead in terms of their individual action plans to balance emissions - their Nationally Determined Contributors (NDCs) - and with greater tolerance for the least developed countries and small islands developing States in terms of global emissions' peaking and NDCs. In contrast to the Kyoto Protocol, the Paris Agreement does not establish emission reduction and limitation targets for individual Parties. Instead, it formulates an overall climate change goal and calls on Parties to contribute to this goal. It is up to the countries to decide how and how much they can contribute to meeting that goal (Streck and Keenlyside). Another achievement of the Paris Agreement is the importance given to market approaches in international efforts to combat climate change, accompanied by a 'framework for non-market approaches to sustainable development' (Article 6.9). In response, climate action from nonstate actors like the retail industry, has grown rapidly (Hsuet al., 2016), with commitments to align energy-performance targets to those proposed by the Agreement.

Other regulations have contributed to climate change action in the retail sector, such as the Montreal Protocol (which set to phaseout hydrofluorocarbon emissions by 2036) and at the European level, by the EPBD (European Parliament, 2010) and the Energy Efficiency Directive (European Parliament, 2018), promoting the improvement of the energy performance of buildings. Non-state actors, especially those with an important carbon footprint like corporate retail, can contribute significantly to countries' ability to mitigate emissions by pursuing ambitious climate action. By peaking and reducing emissions as soon as possible, retailers can help to meet the nations' goals expressed in the Paris Agreement and avoid the worst impacts of climate change (Levin and Rich, 2017).

In parallel, strategy is a comprehensive plan, made to accomplish the organizational goals. It is a game plan, chosen to achieve the organisational objectives, gain customer's trust, attain competitive advantage and acquire a market position. In particular, environmental proactive management practices are commonly associated with benefits such as waste minimization, reducing environmental risks, energy use and material needs (Carballo-Penela and Castromán-Diz, 2015). Retailers are evidence that corporate sustainability is a voluntary custommade process with each organization choosing their own specific ambition and approach. This approach should meet the organization's aims and intentions (policy), and be aligned with the organization strategy, as an appropriate response to the circumstances in which the organization operates (Marrewijk, 2003). 
Additionally, practice is the organised way in which an individual or a group carries out a particular activity. Energy-related building practice refers to the building solutions that enable retailers to achieve energy strategy goals, reducing energy consumption and GHG emissions (Galvez-Martos et al., 2013).

This study is unique in comparing the policy, strategy and energyrelated building solutions of the highest revenue retailers, based on the sustainability/CSR reports of the reporting periods 2014-2015 and 2016-2017. Four questions were tested in the present study: i) what has changed in retailers' policy, strategy and energy-related building solutions with the Paris Agreement?, ii) how do retailers' energy commitments relate to the targets proposed by the Paris Agreement?, iii) what are the greatest contributions in policy, strategy and energy-related building solutions to decarbonize the retail sector and iv) what trends can be expected from retail corporate action on climate change for the future?

Identifying these policies, strategies and energy-related building solutions across the retail industry would provide an example of the potential contribution of specific CSR issues leading to climate change mitigation, namely in terms of energy consumption and GHG emissions, thus empowering stakeholders in environmentally driven decisionmaking. In addition, current trends in the retail sector point at future low-carbon developments (in terms of reducing GHG emissions up to 80-95\% (European Commission, 2011)) in the areas of store operations, supply chain and product stewardship (RILA - Retail Industry Leaders Association, 2017) (Deloitte, 2018), which can be of interest to retail business owners, suppliers and technology industries. The challenge and the objective - of this paper is to understand key policies, strategies and energy-related building solutions that can foster the decarbonization of the retail sector, thus contributing to climate change mitigation.

\section{Materials and methods}

A qualitative comparison was performed regarding the policy, strategy and energy-related building solutions of the top 27 highest revenue retailers in the world ranked according to their revenue. The data was collected online from sustainability/CSR reports published on retailers' websites, due to the international dimension of the sampled retailers. Sustainability/CSR reports of two reporting periods were analysed: of Fiscal Years (FY) 2014-2015 and 2016-2017, as to establish differences in corporate policy, strategy and energy-related building solutions before and after the Paris Agreement respectively.

The sample of the top 27 global retailers was chosen based on the Deloitte and Stores Media's ranking (DeloitteStores Media, 2016) on the global powers of retailing. The ranking of these global retailers at the top of the hierarchy is based on the retail sales revenue achieved. The selected 27 retailers represent about $50 \%$ of the retail sales of the top 250 global retailers (Table 1) presented in this ranking.

The sample was limited to 27 global retailers due to the exploratory character of the research. Amazon, which was part of the initial sample, was excluded from the study since it operates exclusively online. Each analysed retailer has on average 6.165 stores and 12 million $\mathrm{m}^{2}$ of sales area. In total, these retailers represent USD 2,241,035 million in revenue, 166.466 stores and 262 million square meters of sales area, which is an indication of the representativeness of the sample. Despite differences in the retail sector based on for example geographic location or business typology, international retailers tend to replicate their business model across the different countries where they operate, which promotes an increasing heterogeneity of the sector. In addition, the presence of the sampled retailers in many countries can trigger a multiplying effect with regards to sustainability, namely in the implementation of effective policies, strategies and building practices aiming at the pursuit of increased business resilience and environmental performance. Moreover, these retailers are leaders in their sector and therefore a good source of multi-case studies and best practices.

Four main steps were considered in this study (Fig. 1).
In step 1 (Literature review and desk research), a review of the state of the art was carried out regarding corporate social responsibility, governance, corporate policy and strategy and energy-related building solutions in retail buildings. For each identified retailer, policy, strategy and energy-related building practice data were searched by the authors online, in retailers' websites. Data included sustainability/CSR reports, environmental, energy or climate change policies and other energyrelated building solutions data (Walmart, 2015; Walmart, 2018; Costco Wholesale, 2014; Kroger, 2016; Kroger, 2018; Lidl, 2015; Tesco, 2014; Tesco, 2018a; Carrefour, 2015; Carrefour, 2017; Aldi, 2015; Aldi, 2017; Metro Group, 2014; Metro Group, 2017; Home Depot, 2015; Walgreens, 2017; Walgreens, 2015; Target, 2014; Target, 2018; Auchan, 2015; Auchan, 2017; CVS Health, 2015; CVS Health, 2017; Casino, 2014; Casino, 2017; Aeon, 2015; Aeon, 2017; Edeka, 2015; Lowes, 2015; Lowes, 2017; SevenI, 2017; IKEA, 2016, 2018; ITM, 2018; Sainsbury, 2016, 2018; Seven and I, 2016; Rewe, 2017a; Rewe, 2015; Leclerc, 2016; Wesfarmers, 2016; Wesfarmers, 2018; Woolworths, 2015; Woolworths, 2018; Koninklijke Ahold, 2016; Koninklijke Ahold, 2015; Best Buy, 2015; Best Buy, 2018). For each retailer, only the most recent and available sustainability/CSR reports were considered so as to compare the most updated data; in the case of the first reporting period, sustainability/CSR reports preferably from 2015 were analysed, whereas in the case of the second reporting period, sustainability/CSR reports preferably from 2017 to 2018 were analysed.

Most screened retailers (78\%) followed the Global Reporting Initiative (GRI) standards to report sustainability practices in their business operations. They also resort to the Greenhouse Gas (GHG) Emissions' Protocol (89\%) or to the Carbon Disclosure Project (81\%) as measurement tools to track the impacts of their business regarding climate change.

To ensure permanent access to the data that support the presented results, all internet references cited in our study were compiled in a data repository ([dataset 1] in § References).

In step 2 (Characterization of retailers), the country of origin of the selected 27 highest revenue retailers was investigated (Fig. 2). Out of these, 19 food retailers and eight non-food retailers were analysed. The food typology included 8 hypermarkets' retailers, 7 supermarkets' retailers, 2 discount stores' retailers, 1 convenience stores' retailer and 1 cash \& carry retailer. The non-food typology included 2 drug stores/ pharmacies' retailers, 1 department stores' retailer, 1 home improvement retailer, 1 shopping centres' retailer, 1 furniture and decoration retailer and 1 warehouse club retailer. Even though some retailers had a mixed typology of store formats in their business portfolio, these were characterized as food or non-food retailers according to the predominant number of stores in each format. The geographical provenance of the sampled retailers was attributed according to their country of origin, despite the fact that most of the analysed retailers operate stores in more than one country. All of the studied retailers were from developed countries, with most of them being European (52\%). The remaining analysed retailers were American (33\%), Japanese and Australian (7\% each) (Fig. 2).

In step 3 (Data collection), data were organized in different tables according to the variables policy, strategy and energy-related building practice, following the methodology of Sullivan and Gouldson (2013) and Balan (2010). Maximum variation sampling was selected to identify key dimensions of variations and shared patterns that cut across cases and derive their significance from having emerged out of heterogeneity (Suri, 2011). By employing maximum variation sampling with multi-case study sampling, we intend to identify essential and variable features of a phenomenon as experienced by diverse stakeholders in order to facilitate informed decision-making.

Data organization was made in the following way: CSR/sustainability reports were searched for recurring themes, which were recorded under each variable's table, to identify core consistencies and meanings (i.e. patterns) (Miles and Huberman, 1994; Patton, 2002). These patterns were then sorted into categories, according to internal 


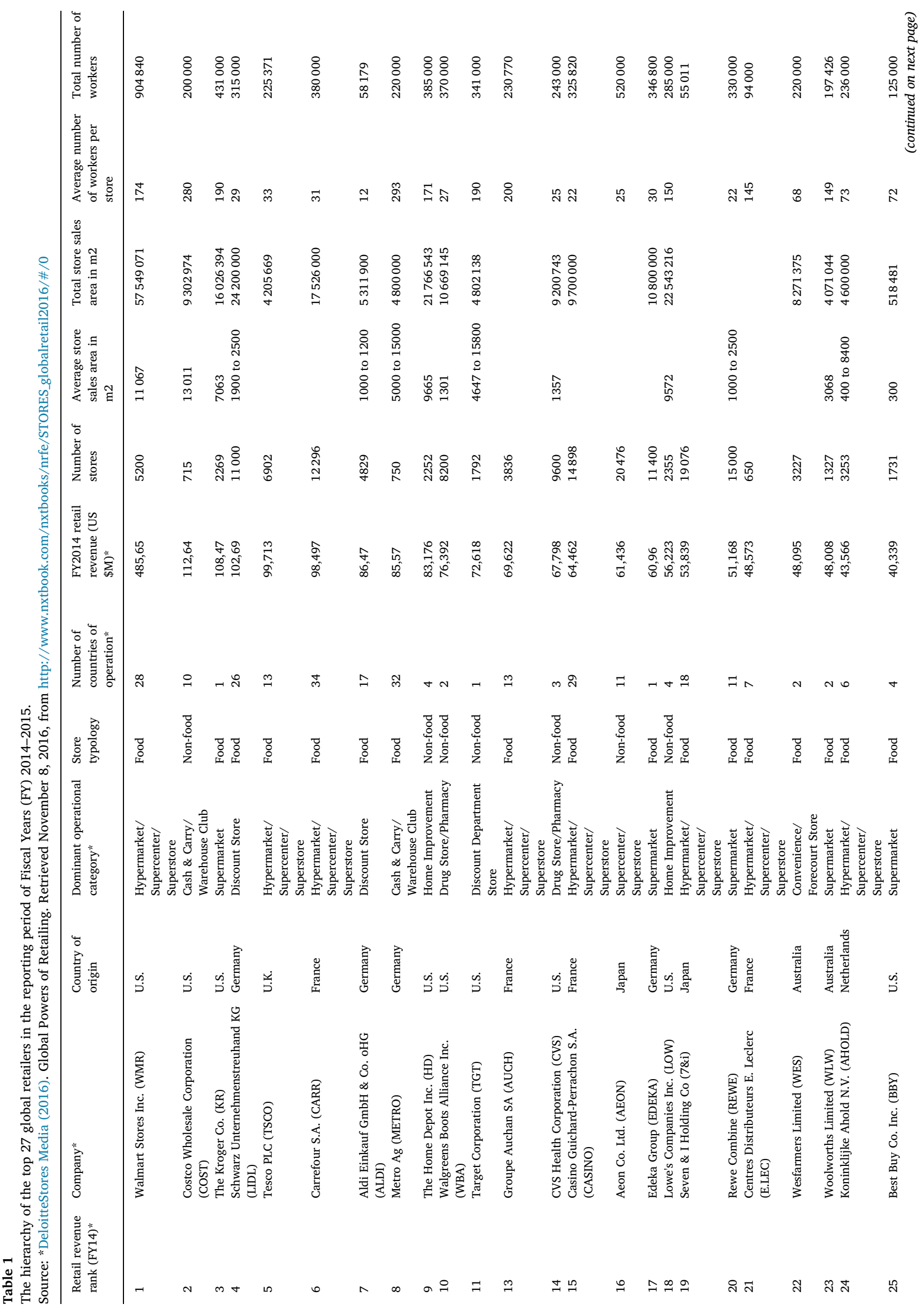


heterogeneity (the extent to which the data belonging in a given category hold together) and external heterogeneity (the extent to which differences among categories are clear). They were also validated by all authors to be reasonably inclusive of the analysed data so as to cover our research questions. Hence, for each variable, data were organized according to the most general category that could embrace each of the identified listed measures. To cross-check data, once all the measures were listed, they were coded as search words and sustainability/CSR reports were analysed in search of these words. Only measures that were referenced by more than $10 \%$ of retailers were included in the presented tables. The original grids used to code all data were compiled in a data repository ([dataset 2] in § References).

In step 3.1 ("Policy" data collection), the data retrieved for the variable "policy" was organized in Table 4 under the categories: (i) CSR Principles and Policy, (ii) ONG Partnerships", (iii) Sustainability Indexes", (iv) Certification Systems and (v) Reporting Standards (see Table 4 in section $\S$ Appendices).

In step 3.2 ("Strategy" data collection), the data retrieved for the variable "strategy", was organized in Table 5 under the categories: (i) Health and wellness, (ii) Product safety, (iii) Transports, (iv) Waste, (v) Supply chain, (vi) Social development (also referred to as "People" or "Community" by retailers), (vii) Governance, (viii) Disaster relief and prevention, (ix) Ethical sourcing, (x) Water, (xi) Energy, (xii) Natural resources, (xiii) Animal welfare, (xiv) Sustainable farming, (xv) Sustainable sourcing, (xvi) Environmental sustainability and (xvii) Digital innovation/e-commerce (see Table 5 in section $\S$ Appendices). These categories supported and extended those described by Corporate Register (2013) as usual reported material issues, reflecting also new concerns that have matured in recent CSR reporting, such as digital innovation.

In step 3.3 ("Energy-related building solutions" data collection), the data retrieved for the variable "energy-related building practice", data were organized in Table 6 under the categories: (i) Bioclimatic architecture, (ii) HVAC systems, (iii) Refrigeration systems, (iv) Energy systems and (v) Renewable energy sources (see Table 6 in $\S$ Appendices). The reported energy-related categories were those with the highest impact in retailers' energy consumption profile, as confirmed by Schönberger et al. (2013).

In step 4 (Data analysis), a comparative analysis was carried out for all the presented categories of the three variable studies (policy, strategy and energy-related building practice) regarding the two analysed periods (Figs. 3-5). Data was searched for divergence in terms of deviant cases that did not fit the dominant identified patterns (included in [dataset 2]), as well as rival explanations for the results (Miles and Huberman, 1994; Patton, 2002). To increase the reliability of the data analysis, the authors have resorted to the triangulation technique, checking for their consistency with other authors' theories and data sources (see $\S$ Results and Discussion section).

In step 5 (Critical assessment of decarbonizing strategies following the Paris Agreement), a comparison analysis was carried out between retailers, based on the percentage of retailers that cited each of the listed categories' measures in their sustainability/CSR reports and on its evolution regarding the two reporting periods, in order to identify differentiating measures that could lead to the decarbonization of the sector and to a higher environmental performance. In addition, in order to track retailers alignment to that of their nations in terms of the NDC's ratified under the Paris Agreement, a comparison was performed between the NDCs of the nations of the studied retailers and their own corporate climate change commitments (Tables 2-3).

\section{Results and discussion}

The evolution of retailer's policy, strategy and energy-related building practice to decarbonize the sector in the aftermath of the Paris Agreement is addressed in the following subsections. Retail is a diverse but highly concentrated industry in terms of ownership and sales, as 


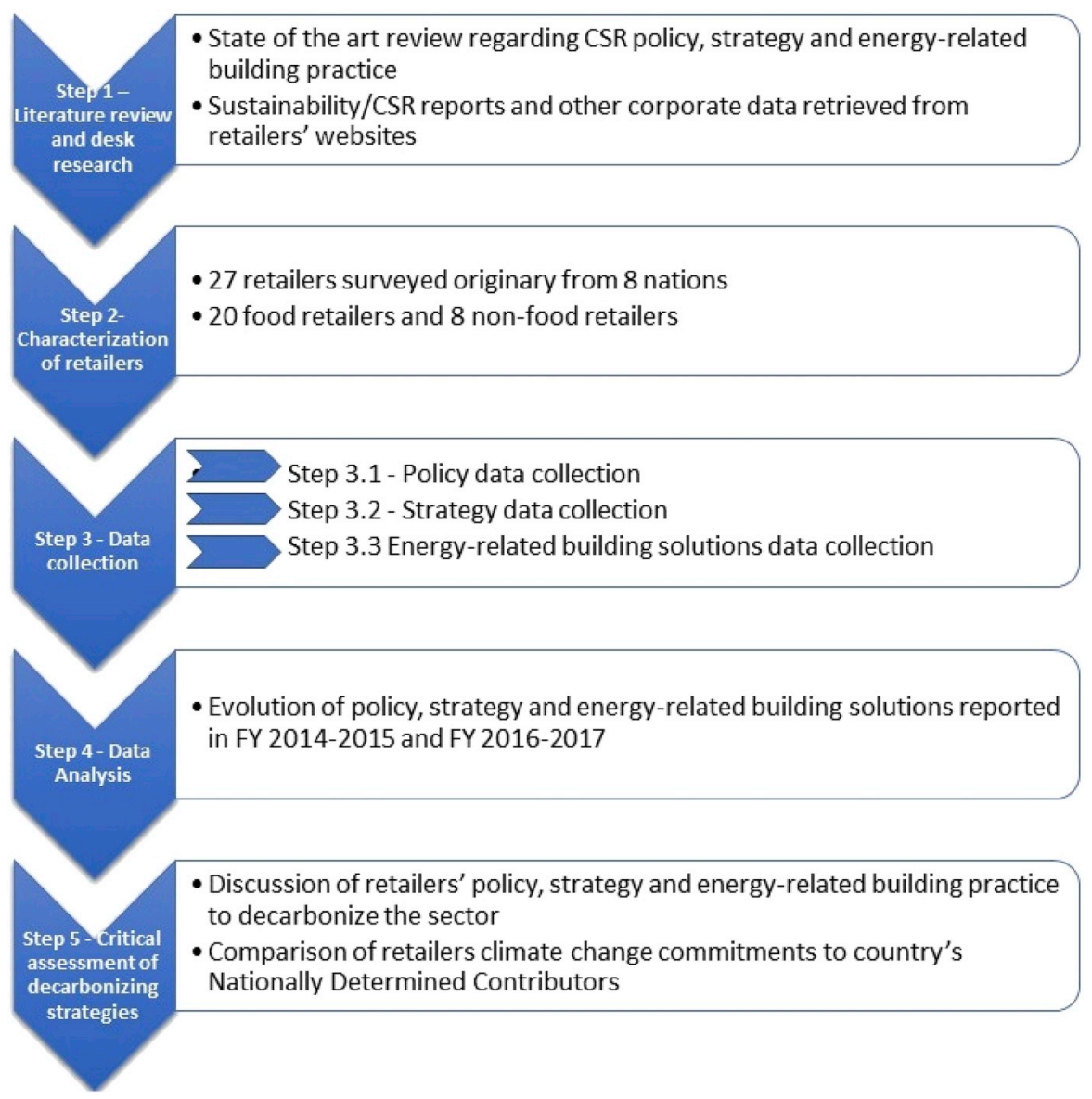

Fig. 1. Methodology diagram.

evidenced by the 27 highest revenue companies analysed in the present study. Because of its broad reach, the retail sector has the potential to affect society in a way that not many other industries can. The level of concentration and similarities between companies allow for easier dissemination of corporate best practices across the sector, or even across other industries with large operational emissions (specifically building and transport-related) (Sullivan and Gouldson, 2016).

According to Sullivan and Gouldson (2013), retailers are already in a position to reduce operations and transport' GHG emissions by more than $1.5 \%$ per annum over the period through to 2020 . In addition, the variability of the energy and carbon intensities found in retailers' sustainability/CSR report shows an already available capacity to reduce energy demand by a factor of 3 and carbon footprint by a factor of 6 (Ferreira et al. 2018), proving that it is possible for commercial buildings to become $70-80 \%$ more energy-efficient, as sought by the Energy Performance of Buildings Directive (European Parliament, 2010).

\subsection{Evolution of CSR policy in retail}

The compelling subscription of the Paris Agreement pledge by

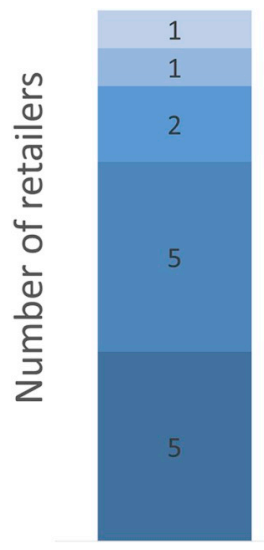

Europe

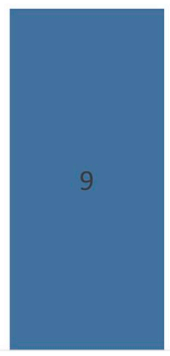

U.S.

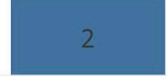

Japan
Sweden

Netherlands

- U.K.

- France

- Germany

\section{Retailers' continent / country of origin}

Fig. 2. Distribution of the 27 highest revenue retailers per continent/country of origin. 


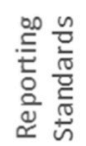
Greenhouse Gas (GHG) Emissions' Protocol Global Reporting Initiative (GRI)

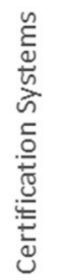

505001

ISO14001

Other green building certification schemes

LEED

BREEAM

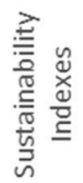

FTSE 4Good Index

Dow Jones Sustainability Index

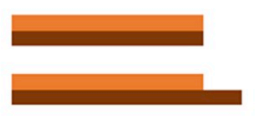

Paris Agreement UN Global Compact Principles

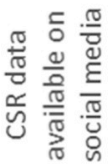

Environmental/Sustainability policy Sustainibility report

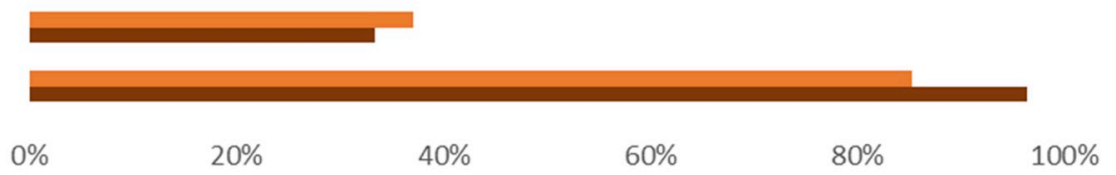

- Reporting period 2016-2017

- Reporting period 2014-2015

Fig. 3. Retailers' CSR policy measures addressed by them in the reporting periods of FY 2014-2015 and FY 2016-2017.

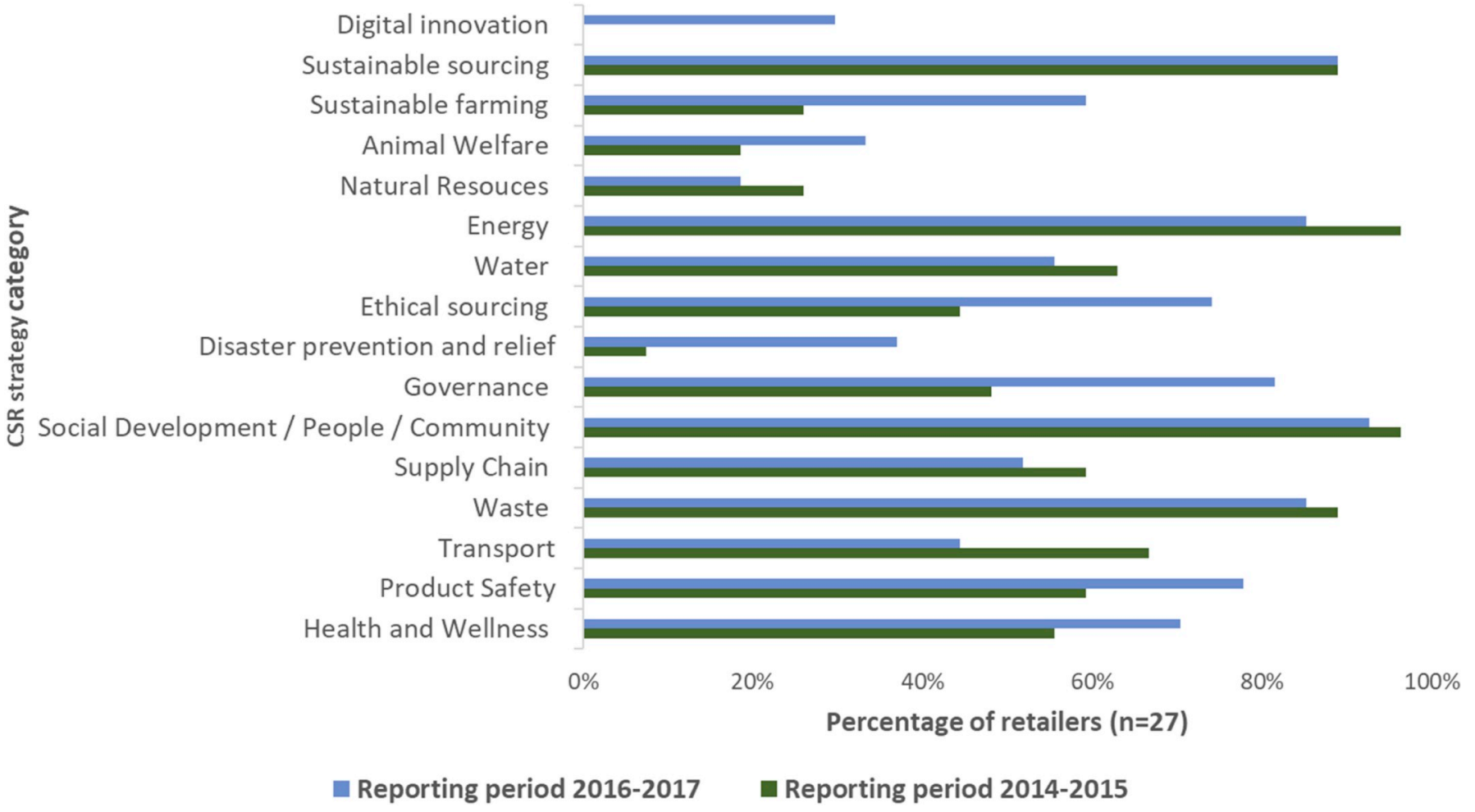

Fig. 4. Retailers' CSR strategy measures addressed by them in the reporting periods of FY 2014-2015 and FY 2016-2017. 


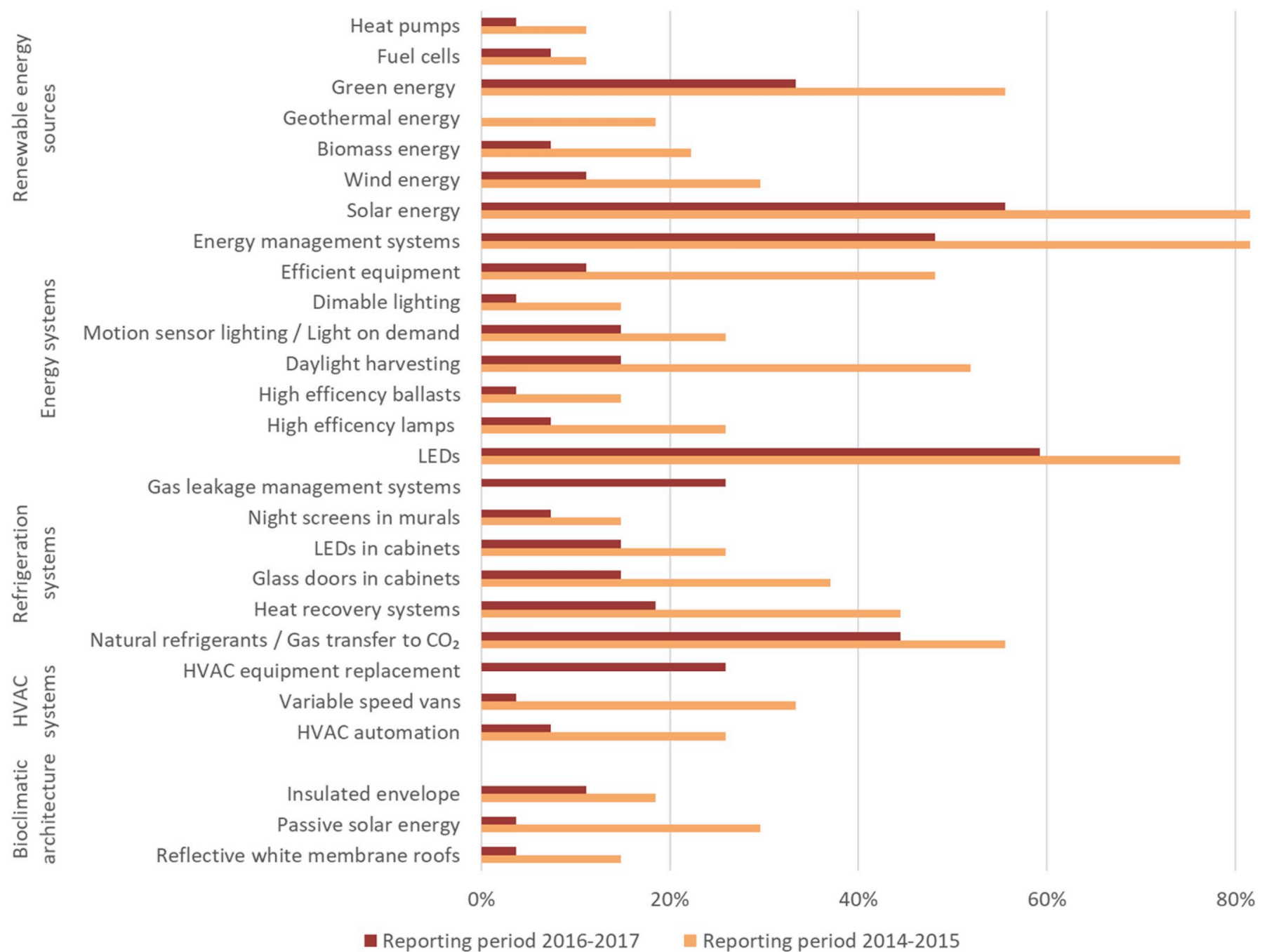

Fig. 5. Retailers' energy-related building solutions addressed by them in the reporting periods of FY 2014-2015 and FY $2016-2017$.

retailers attests to their readiness for climate-change action and is in line with the findings of Kinley (2017), according to which non-state actors are becoming the engine of both mitigation and adaptation in climate-change action. The newfound international understanding regarding GHG emissions that arose from the Paris Agreement has signalled retailers that carbon regulation lies ahead, thus supporting the pursuit of voluntary environmental sustainability programs and standards as an anticipation of sustainability legislative changes. Other sustainability business drivers associated with climate change refer to concerns about rising energy prices (Christina et al., 2015), customers preference, sustainable growth and access to resources. In fact, a management culture based both on legal requirements and voluntary obligations is transversal to many retailers, since being ahead of legislation increases competitiveness (Cowanet al., 2010).

Almost all retailers covered by this paper (85\%) have produced yearly sustainability/CSR reports. When comparing their reports in terms of business policy, an enhanced focus on sustainability is found in 2016-2017 reports, namely with $63 \%$ retailers publicly supporting and aligning energy-performance targets to those of the Paris Agreement pledge, which is a new entry in the latest sustainability/CSR reports (Fig. 3).

Our results also show that standardized reporting has increased over time (an average of $15 \%$ in 2016-2017), a trend that confirms the findings of Corporate Register (2013) and reflects retailers' choice for Global Reporting Initiative (GRI) and GHG Emissions' Protocol frameworks as the two most relevant sustainability frameworks. The adherence to reporting standards like the GRI, the GHG Emissions' Protocol or the Carbon Disclosure Project (CDP) - followed by 78\%, $89 \%$ and $81 \%$ retailers respectively - confirms that investors positively value these reporting initiatives, as suggested by Berthelot et al., 2012.

In addition, results also show that retailers are converging in terms of orientating business principles, with $78 \%$ of retailers subscribing to the United Nations Global Compact (UNGC) principles. This slow but steady adhesion to the UNGC framework by retailers follows the global corporate adherence trend described by Corporate Register (2013). As GRI and UNGC have a Memorandum of Understanding, UNGC principles can be correlated to the GRI framework, thus facilitating the reporting process.

The adherence to UNGC principles goes beyond the "institutional mimetics" that is frequently observed in corporate retail reporting as a way to improve business image and legitimacy (Baker et al., 2012). Hence, contrary to what was suggested by Reilly and Hynan (2014) and Cowanet al. (2010), our findings suggest that retailers are converging on the selection of format and metrics used for sustainability reporting over time, recognizing the need for transparency and accountability, further stressed with the Paris Agreement.

No expressive differences were found in the measures "environmental policy" or "sustainability policy" over the two reporting periods, often associated with an environmental management system (EMS). Companies can resort to the use of EMS with varying goals, and differences in environmental performance between retailers, despite the use of the same meta-standard, can be explained by diverging levels of 
Table 2

Highest revenue retailers' climate change commitments.

\begin{tabular}{|c|c|c|}
\hline Revenue rank & Company & Climate Change Overarching Commitments \\
\hline 1 & Walmart Stores Inc. & $\begin{array}{l}\text { - Reduce operations emissions by } 18 \% \text { by } 2025 \text { and source } 50 \% \text { energy from renewable sources. Overarching goal to be } \\
100 \% \text { supplied by renewable energy. }\end{array}$ \\
\hline 2 & Costco Wholesale Corporation* & - * \\
\hline 3 & The Kroger Co. & - Reduce energy consumption by $40 \%$ by 2020 , and then shift toward renewable energy sources \\
\hline 4 & Schwarz Unternehmenstreuhand $\mathrm{KG}^{*}$ & $\bullet *$ \\
\hline 5 & Tesco PLC & - Become a zero-carbon business by 2050 . Source $65 \%$ electricity from renewable sources by 2020 and $100 \%$ by 2030 \\
\hline 6 & Carrefour S.A. & - Reduce CO2 emissions by $40 \%$ by 2025 and by $70 \%$ by 2050 (compared to 2010 baseline) \\
\hline 7 & Aldi Einkauf GmbH \& Co. oHG & - Reduce emissions by $40 \%$ by 2021 (compared to 2015 baseline) \\
\hline 8 & Metro Ag & - Reduce GHG emissions by $50 \%$ between 2011 and 2030 \\
\hline 9 & The Home Depot Inc. & - No target presented \\
\hline 10 & Walgreens Boots Alliance Inc. & - Reduce energy consumption $20 \%$ by 2020 \\
\hline 11 & Target Corporation & $\begin{array}{l}\text { - Reduce emissions by } 35 \% \text { by } 2020 \text {, by } 60 \% \text { by } 2030 \text { and by } 100 \% \text { by } 2050 \text {. Source } 65 \% \text { renewable energy by } 2020 \text { and } \\
100 \% \text { by } 2030\end{array}$ \\
\hline 12 & Groupe Auchan SA & - Reduce energy consumption $20 \%$ from 2014 until 2018 \\
\hline 13 & CVS Health Corporation & - Reduce carbon intensity by $15 \%$ by 2018 (accumulated $45 \%$ against a 2010 baseline). \\
\hline 14 & Casino Guichard-Perrachon S.A. & - No target presented \\
\hline 15 & Aeon Co. Ltd. & - Reduce energy consumption by $50 \%$ by 2020 \\
\hline 16 & Edeka Group* & $\bullet *$ \\
\hline 17 & Lowe's Companies Inc. & - Reduce U.S. operations carbon emissions $20 \%$ by 2020 \\
\hline 18 & Seven \& I Holding Co & - Reduce emissions by $20 \%$ by 2025 \\
\hline 19 & Rewe Combine & - Reduce GHG emissions by $50 \%$ by 2022 \\
\hline 20 & Centres Distributeurs E. Leclerc & - No target presented \\
\hline 21 & Wesfarmers Limited & - No target presented \\
\hline 22 & Woolworths Limited & - Reduce carbon emissions by $10 \%$ (compared to 2015 baseline) \\
\hline 23 & Koninklijke Ahold N.V. & - Reduce emissions by $30 \%$ (compared to 2008 baseline) \\
\hline 24 & Best Buy Co. Inc. & - Reduce carbon emissions by $60 \%$ by 2020 and become carbon neutral by 2050 \\
\hline 25 & The IKEA Group & - Become a circular business built on clean, renewable energy and regenerative resources by 2030 \\
\hline 26 & ITM Développement International & - Source $25 \%$ renewable energy across group operations by 2025 \\
\hline 27 & J Sainsbury plc & - Reduce emissions by $65 \%$ by 2020 \\
\hline
\end{tabular}

Key: * Companies that did not present a sustainability/CSR report after the reporting period of FY 2014-2015.

corporate internalization of the EMS in terms of strategies and daily operational procedures. According to Testa et al. (2017), deeper internalization of an EMS can be achieved with wider and more frequent employee involvement or higher integration with other management and operational tools, namely staff training, energy audits and sustainability apps.

The reported use of ISO 14001 did not increase either in the two reporting periods, contrary to the use of ISO 5001 (15\% versus 26\%), which points to the increased importance of a more structured framework for energy management in retailers' corporate agenda. It can also be an indicator of the recognized priority given to energy management, as a cost reduction tool and with the potential to address climate change. Here too, different levels of ambition in terms of energy reduction targets can lead to varying levels of success in the adoption of the ISO 5001 standard.

According to the results, there is a slight decrease in the use of green building certification schemes $(-10 \%$ on average). The fact that retailers are not commenting on the use of these schemes in their sustainability/CSR reports does not mean that green building initiatives were not achieved, as suggested by Cowanet al. (2010), but could rather indicate that sustainability reporting is above all a reflex of what is perceived as more important for a company to communicate (see further discussion in section $\S 3.3$ ). In fact, $66 \%$ of the studied retailers reported the use of a Green Building Certification System, which is

Table 3

Nationally Determined Contributors (NDCs) ratified by retailers' nations under the Paris Agreement and Greenhouse Gas (GHG) emissions peak by decade.

\begin{tabular}{|c|c|c|}
\hline Country & Nationally Determined Contributions (NDCs) & GHG emissions peak by decade \\
\hline Australia & - To reduce GHG emissions by $26-28 \%$ by 2030 (compared to 2005 baseline) & - GHG emissions peaked by 2010 \\
\hline France & $\begin{array}{l}\text { - To reduce GHG emissions by } 40 \% \text { between } 1990 \text { and } 2030 \text { * } \\
\text { - To reduce GHG emissions by } 75 \% \text { by } 2050 \\
\text { - To cut final energy consumption to } 50 \% \text { by } 2050 \text { (compared to } 2012 \text { levels), with an intermediate target of } \\
20 \% \text { or less by } 2030 \\
\text { - To reduce primary energy consumption from fossil fuels by } 30 \% \text { by } 2030 \text { (compared to } 2012 \text { levels) } \\
\text { - To source } 40 \% \text { renewable energy by } 2030\end{array}$ & - GHG emissions peaked by 2000 \\
\hline Germany & $\begin{array}{l}\text { - To reduce GHG emissions by } 50 \% \text { by } 2030 \text { (compared to } 1990 \text { levels). To source 100\% renewable energy } \\
\text { by } 2050\end{array}$ & - GHG emissions peaked by 1990 \\
\hline Japan & - No target for GHG emissions reduction has yet been assigned from 2013 to 2020 & - Commitment to peak GHG emissions by 2020 \\
\hline Netherlands & - To reduce GHG emissions by at least $40 \%$ by 2030 (compared to 1990 levels)* & - GHG emissions peaked by 2000 \\
\hline Sweden & $\begin{array}{l}\text { - To reduce GHG emissions by } 85 \% \text { by } 2045 \text { (compared with } 1990 \text { levels) and thereafter achieve negative } \\
\text { emissions }\end{array}$ & - GHG emissions peaked by 2000 \\
\hline U.K. & $\begin{array}{l}\text { - To reduce GHG emissions by } 20 \% \text { by } 2020 \text { (compared with } 1990 \text { levels) } \\
\text { - To reduce GHG emissions by } 80 \% \text { by } 2051\end{array}$ & - GHG emissions peaked by 2000 \\
\hline U.S. & - To reduce $26-28 \%$ GHG emissions by 2025 (compared to 2005 baseline) & - GHG emissions peaked by 2010 \\
\hline
\end{tabular}

Key: *Collective target of the European Commission.

Abbreviations: GHG - Greenhouse Gas Emissions; NDCs - Nationally Determined Contributions. 
usually chosen according to retailers' geographic provenance. BREEAM, as a European certification system, was chosen uniquely by European retailers. Besides BREEAM, European retailers report the use of other national building certification schemes, such as Germany's Sustainable Building Council (DGNB), France's Haute Qualité Environmental (HQE) or Sweden's Green Building Council (SGBC). In contrast LEED, as an American certification system, was chosen by American and European retailers, which makes it more popular as an international green building certification tool. The Energy Star certification has also been reported by four American retailers.

The voluntary standards adopted by retailers, whether in CSR reporting or in certification schemes seem to indicate that retailers' approach to CSR issues are not based on instrumental theories alone that defend the maximization of profits to shareholders (Garriga and Melé, 2013). Contrarily, they seem to encompass a mix of conceptual theoretical CSR frameworks as to foster competitive advantage. Voluntary standards also tend to signal positive environmental performance (Parguel et al., 2011; Kim and Lyon, 2015; Hahn and Luelfs, 2014). In fact, in the case of CSR communication, a poor sustainability rating can damage corporate brand evaluation (Parguel et al., 2011). Hence, according to Parguel et al. (2011), sustainability ratings could act to deter greenwashing and encourage virtuous firms to persevere in their CSR practices (). Likewise, the GRI reporting standards, followed by most retailers, help to overcome greenwashing tendencies by reporting both positive and negative aspects of sustainability performance (Hahn and Luelfs, 2014). Greenwashing practices tend to decrease when companies experience greater scrutiny from external stakeholders such as regulators or NGO's, which may also apply in the case of the analysed retailers (Kim and Lyon, 2015).

A natural resource-based view of the firm as proposed by Hart (1995), seems to be adopted by retailers, which has into consideration the limited resources of the environment. Retailers' adherence to the Carbon Disclosure Program or to voluntary standards and its positive relationship with environmental performance points in this direction (Giannarakis et al., 2017). Cause-related marketing is another CSR strategy followed by retailers that seeks to gain competitive advantage, by associating the brand with the ethical or social responsibility dimension (Smith and Higgins, 2000). Retailers' partnerships with ONG's, or their subscription of the UNGC principles are an example of such; more, they are a form of enlightened self-interest and a win-win situation as both the company and the charitable cause receive benefits, as pointed by Smith and Higgins (2000). Retailers' adherence to the UNGC principles also attests to two other CSR theories followed by retailers: the universal rights ethical theory and the corporate citizenship political theory, focused on rights, responsibilities and partnerships of business and society as to improve local community and environment conditions (Garriga and Melé, 2013).

Likewise, the integrative social contract theory (Donaldson and Dunfee, 1994) as another political CSR theory, can also be observed amongst the studied retailers, in which two levels of consent are assumed for social responsibilities: a theoretical macrosocial contract and a real microsocial contract. The macrosocial contract provides fundamental rules for social contracting whereas the microsocial contracts shows agreements that are binding within partners. In the case of retail, one can compare the macrosocial contract rules to those settled by the Paris Agreement or other legal regulations, and the microsocial contract to the influence retail exerts over its supply chain (see section $\S 3.2$ ) or contractors (see section $\S 3.3$ ).

Finally, the ethical sustainable development theory seems to encompass many of the aspects of the previously mentioned theories and has become a major guiding framework for retailers' CSR approaches. This concept requires the integration of social, environmental, and economic considerations taken in the decision-making process (Garriga and Melé, 2013). Nonetheless and according to Van Marrewijk and Werre (2003), CSR policy and strategy is seen as a custom-made process that can cover parts of different CSR theories.

\subsection{Evolution of CSR strategy in retail}

Our results confirm that the reduction of energy consumption and GHG emissions remain in sustainability/CSR reports' agenda during the last analysed period (FY 2016-2017), as detailed in Table 2.

In fact, in terms of environmental impact, in retailers' latter sustainability/CSR reports there is a greater stress on absolute GHG emissions' reduction targets, and a commitment to reduce GHG emissions over a longer time horizon (up to 30 years). Indeed, companies that disseminate GHG emissions information voluntarily, namely via the Carbon Disclosure Project - which is the case of the majority of the analysed retailers - tend to have better environmental performance in terms of GHG emissions (Giannarakis et al., 2017). Retailers that present long-term targets may do so to publicly reinforce their long-term commitment towards climate change. Some retailers also disclose shortterm targets (Carrefour, 2017) (Target, 2018), typically necessary to achieve progress. Reasons to do so may be supported by the voluntary disclosure theory (Dye, 1985) (Verrecchia, 1983), in which a company's high superior environmental performance motivates it to increase its disclosure level to inform stakeholders and promote differentiation.

The effort to increase environmental performance seems to be further extended to retailers' supply chain, with retailers encouraging sourcing teams to improve climate change response, namely in GHG emissions related to manufacturing and transport. Nevertheless, our findings show that retailers diverge in their overarching commitments towards climate change, in terms of energy consumption and GHG emissions reduction goals. About half of the retailers intend to reduce emissions (56\%), from which $15 \%$ aim at becoming carbon neutral and totally supplied by renewable sources by $2030-50$. Another $15 \%$ of retailers intend to reduce emissions by $20-50 \%$ by $2018-2020$. This is consistent with the findings of Christina et al. (2015), placing climate change ethical considerations alongside rising energy prices as drivers for energy reduction targets and strategies.

Overall, countries that have peaked their GHG emissions as early as 1990 are more ambitious in their NDC's (e.g. Germany) than countries that have peaked their GHG emissions a decade later (e.g. France, UK or the Netherlands), two decades later (e.g. Australia and U.S.) or those that have committed to peak GHG emissions in 2020 (e.g. Japan) (Table 3). When comparing the NDCs of retailers' countries of origin to their own climate change commitments, we find that retailers either follow or improve upon GHG emissions reduction targets of their country's NDCs. While the first group of retailers follows a more conservative approach in line with expected future sector policy regulation (e.g. France, Germany and Netherlands, in line with the collective target of the European Commission), the second group of retailers is willing to consider more ambitious business transformations to tackle climate change and improve business resiliency. Differences in retailers' store typology or in revenue were not significant regarding GHG emissions' commitment targets (see Table 7 in $\S$ Appendices). Interestingly, according to Jackson and Apostolakou (2010), firms with headquarters located in coordinated market economies' countries (such as Japan, or continental Europe) may rely on implicit forms of CSR that are embedded within high levels of formal and informal societal regulation. Contrary, firms in coordinated liberal economies' countries (such as UK, USA or Australia) may adopt more extensive and explicit CSR practices (Jackson and Apostolakou, 2010). Our findings suggest evidence of this, with French, Dutch and Japanese retailers' climate change commitments alignment to those of their countries' NDCs. Here, climate change commitments seem to be driven partially by international regulations and partially in consideration of national and subnational regulations where retailers operate. According to Giannarakis et al. (2017), this institutional effect is much stronger in terms of adopting minimum standards than best practices; German and Swedish retailers, in their effort to push climate change commitments further, also support this finding.

In addition, our findings suggest that corporate culture plays an 
important role on retailers' CSR approach (Ferreira et al. 2018), namely in the decarbonizing strategies and goals set by them. Such is the case of a group of three Swedish, English or American retailers, which intend to become carbon neutral by 2050 and 100\% supplied by renewable energy. These targets are well above their country's current NDC's. These retailers are of the food and non-food typology, which suggests that is not culture nor retailer typology the leading driver for sustainable business practice, but rather retailers' individual ambition. Food retailers, with higher energy and carbon intensities due to refrigeration systems, do not shy away from more aggressive GHG emission goals. Japanese retailers are also evidence of the role of corporate culture in retailers' CSR approach, as they intend to reduce GHG emissions by $20-50 \%$ by $2020 / 2025$ when no emissions' reduction target exists in their country's current NDCs. This goes in line with the findings of Kinley (2016), according to whom market approaches found their way into the Paris Agreement, giving them a renewed role in international efforts to combat climate change. Policy at national governmental level plays a role at pushing retailers into energy and carbon efficiency, but it is rather retailers' CSR approach that is a differentiating factor in their commitment to reduce energy consumption and GHG emissions. The differences of energy and carbon goals within European retailers with a common legislative framework, are further evidence of this.

In terms of action to assist GHG emissions' reduction goals, retailers focus on three main areas: transport, supply chain and energy in retail operations. In terms of transport, efforts go into improving fleet efficiency, testing alternative fuels and/or electrifying the truck fleet and expanding e-commerce, which would reduce the need of physical stores and store trips. With up to $90 \%$ of retailers' total GHG emissions coming from supply chains (Walmart, 2018), efforts to improve sustainability in supply chain include the need for business partners to comply with sustainability indexes and targeted measurement tools, mainly in the areas of water, waste and energy. Increasing sustainability in the value chain also includes path efficiency in logistics and more locally produced goods. In terms of energy, retailers first minimize energy consumption as to limit GHG emissions and then shift towards renewable energy sources. Other actions include setting an internal price per tonne of $\mathrm{CO}_{2}$ and applying this price to all emissions-relevant investment decisions (Aldi, 2017).

Our results hint at retailers' commitment towards a low carbon future, which corroborates and extends the findings of Sullivan and Gouldson (2013, 2016). The Paris Agreement seems to have provided the policy certainty that the business sector had been seeking, as it is now clear that overarching future regulation on GHG emissions is inevitable (this is further evidenced by American retailers that have subscribed to the Paris Agreement, despite political withdrawal from the United States). In addition, it seems that companies are learning from the early phases of the transition to a low carbon society (e.g. by increasing energy-efficiency) and are now able to adapt and to support increased energy challenges, such as becoming carbon neutral.

Hence, our results demonstrate that energy is a central issue addressed in CSR reporting (Fig. 4), and a key issue for environmental sustainability (alongside with rising concerns about deforestation and the use of chemicals).

In fact, the issues most addressed in retailers' sustainability/CSR reports over both reporting periods remain unchanged: social development/community, energy (the apparent decrease in the later reporting period is due to the fact that three retailers did not publish a sustainability/CSR report in FY, 2016-2017) and sustainable sourcing, as if analogously linked to the "Triple Bottom Line" paradigm (people, planet and profit), as a guiding pillar for business operation (Elkington, 1994). This is evidence of retailers' adherence to the sustainable development as an ethical theory central to their CSR approaches that include economic, social and environmental aspects of the corporation (Garriga and Melé, 2013). It is also linked to a natural-resource-based view of the firm as a CSR strategy, as proposed by Hart (1995), in which the ecological approach relates to three interconnected strategies: pollution prevention, product stewardship and sustainable development. The pollution prevention strategy includes the CSR subcategories of protect deforestation and reduce the use of chemicals. The product stewardship strategy includes the CSR categories of animal welfare, sustainable farming, sustainable and ethical sourcing, organic products, healthier food, product traceability, product safety and sustainable product packaging. The sustainable development strategy includes the CSR categories of natural resources, energy, water, waste and reducing environmental impact, in which retailers express ambition regarding having a positive impact on people and fostering a circular economy, with zero waste lifestyles (Bluebeam, 2016; Rewe, 2015; Auchan, 2016; Costco Wholesale, 2016; CVS Health, 2016; Edeka, 2016; ITM, 2018; Lidl, 2018; Seven and I, 2017).

Simultaneously, our results show an important increase (30\%) in the role played by corporate governance in retail organizations, namely in terms of environmental and anti-trust compliance. Corporate constitutionalism as a political CSR theory can be observed amongst the analysed retailers, particularly with the rise of the importance of governance. According to Davis (1960), business is a social institution and it must use power responsibly; those who do not do it will tend to lose this power to fitter competitors. This points to the recognition that governance is of paramount importance for business resilience and sustainability, in the sense that it balances the sometimes conflicting interests of stakeholders, as those of investors, customers, suppliers, government and the community; in turn, governance structures define conditions for the responsible use of corporate power, having into consideration the needs of different stakeholders. Through governance, retailers seek to respond to social demands and increase both the company's sensitivity to its environment and also the environments understanding of corporate difficulties (Garriga and Melé, 2013). Environmental and anti-corruption compliance are recently reported governance subcategories that are an example of retailers' adaptation to societal demands. Another example is retailers' evolution of NGOs' partnerships as an adaptation to the pressures exerted by communities, governments, and other institutional forces, as pointed by Garriga and Melé (2013). As business adaptation increases in complexity, the political response to present day challenges (such as climate change) may make the difference between businesses thrive or decline. Nevertheless, retailers are compelled to meet certain standards under the regulations of various countries where they operate, namely in terms of building standards, energy efficiency or renewable energy standards (European Parliament, 2018) (United States Senate, 2015) (United States Senate, 2019). Climate change policies are thus influenced partially by such regulations and partially by voluntary commitments that would otherwise be government's responsibility to institute (Beckers, 2019).

Lastly, results also reveal "Digital innovation" as an emerging retail category, emphasising business transition into the future, namely in terms of e-commerce, cybersecurity and data privacy. In effect, future business growth may have other characteristics than present growth, hence the importance of a structured approach to innovation for increased business resilience, as indicated by Sullivan and Gouldson $(2013,2016)$. Online retail may become a preferable form of sales growth (particularly in developed economies), in opposition to an increase in retail property. Furthermore, as new stores in the future are likely obliged to be nearly-zero energy buildings due to pending energy regulation, store expansion may first evolve towards more cost-effective alternatives, such as the refurbishment of ageing stores or the rehabilitation of declining commercial areas into a new retail business. Hence, with improved transport efficiency and soft mobility, existing retail stores may serve a larger population range, becoming platforms for online sales. Artificial intelligence and the Internet-ofThings will further allow retailers to personalise the shopping experience and to do so at scale, gathering and managing high impact data (Deloitte, 2018). 


\subsection{Evolution of energy-related building solutions in retail}

When comparing energy-related building solutions used in retailers' stores that were reported in 2014-2015 and 2016-2017, there is an overall decrease in the frequency of solutions mentioned in the latest sustainability/CSR reports (Fig. 5). We believe this decrease is not a reflection of sustainable building performance, but rather a reflex of stakeholders' idea of what is most important for a company to publicly communicate. In addition, in each yearly sustainability/CSR report, retailers preferably report on innovative building solutions implemented over that reporting period and on the progress achieved in terms of overall key performance indicators (e.g. energy or carbon intensity), without mentioning all the measures implemented in the past that contributed to increased energy or carbon efficiency. Hence, the range of reported energy-related building solutions may vary according to the accuracy and level of detail of retailers sustainability/CSR reports.

It is consensual for retailers that energy is the top priority when introducing sustainable solutions in retailers' buildings, largely because of the potentially high savings. Hence, our findings support and extend those of Sullivan and Gouldson $(2013,2016)$, corroborating that climate change is not needed as a driver for sustainable building solutions since it is sufficiently justified by financial reasons. In fact, improving energy-efficiency in buildings has been a major focus area for retailers over time, as one of the cheapest ways of reducing both costs and carbon emissions (European Parliament, 2010).

Energy-related building solutions that contribute the most to improved environmental performance are those that allow decreasing the energy consumption of the most energy-intensive store segments, in order: refrigeration, lighting, HVAC and electric appliances. Indeed, according to Schönberger et al. (2013), the average share of energy consumption of a food retailer is $50 \%$ in refrigeration, $25 \%$ in lighting, $20 \%$ in HVAC systems and $5 \%$ in electric appliances and other internal processes. For non-food retailers, the map for the energy consumption of a store depends more on business typology though lighting, HVAC systems and electric appliances remain the three most important energy consumption segments.

Our results show that the top high-performance building solutions most addressed in retailers' sustainability/CSR reports over both reporting periods remain unchanged in energy systems and are economically and environmentally driven: photovoltaic technology, energy management and for food retailers, natural refrigerants. In fact, the top high-performance solutions mentioned by retailers in the present study are in line with the findings of Sullivan and Gouldson (2013), Richman and Simpson (2016) and Ochieng et al. (2014), naming LED lighting, refrigeration and HVAC as key areas where attention is typically on improving energy efficiency. The replacement of old rooftop units by more efficient equipment can reduce the energy consumption of HVAC systems by $20 \%$, improving thermal conditions for customers at the same time (CommONEnergy Project, 2013a). In turn, $\mathrm{CO}_{2}$ based refrigeration and glass doors in frozen cabinets can reduce energy consumption by $40 \%$, whereas LED lighting systems can reduce energy consumption by $50 \%$, when compared to fluorescent T8 lighting (CommONEnergy Project, 2013b; Schönberger et al., 2013). In terms of refrigeration systems, retailers continue to shift to natural refrigerants with lower global warming potential, such as carbon-dioxide, ammonia, propane, glycol and water-based refrigeration systems, alongside with GHG and gas leakage management systems. For food retailers, GHG emissions' management systems are important tools to decrease their carbon footprint, since $30 \%$ of it can derive from refrigeration systems' gas leakage (Schönberger et al., 2013; Jenkins, 2008). The entry of this building solution in the latest sustainability/CSR reports points to retailers' increased attention in key systems that can minimize their carbon footprint.

Nonetheless, the fact that some energy-related building solutions are sporadically reported by retailers points to differences in the way these solutions may be incorporated across retailers' property portfolio. This could suggest that retailers are greenwashing, or just that some measures, despite being good investments (e.g. reflective white membrane roofs or variable speed ventilators), may only have been tested in pilot stores and not rolled out across retailers' property portfolio. Opposite, firms may choose to brown wash - omitting environmentally friendly actions or won green awards - to avoid experiencing negative abnormal returns (Kim and Lyon, 2015).

To mitigate Scope 1 GHG direct emissions, namely stationary combustion for comfort heating, food retailers can recover waste heat from the refrigeration cycle, hence suppressing the need for additional store heating. To address fugitive emissions resulting from the unintentional release of GHG from refrigerant systems, retailers can invest in gas leakage detection and improved maintenance in HVAC and refrigeration systems. Gas transfer to $\mathrm{CO}_{2}$ in refrigeration systems also ranks high for food retailers, because of its impact on the company's overall carbon footprint. In addition, to mitigate Scope 2 GHG indirect emissions from the consumption of purchased electricity, retailers can invest in the on-site production of renewable energy, in the purchase of green energy or in offsetting methods. Energy efficiency solutions minimising energy consumption are the first step to decrease emissions from the electrification process.

Hence, sustainable high-performance building solutions that will be used in the future will be those that minimize energy demand (integrating high energy-efficient equipment), coupled with the on-site production of renewable energy - or the purchase of available 'green' electricity when such is not viable. The wide array of high-performance energy-efficient solutions used by retailers shows that there is no "silver bullet" to achieve nearly-zero energy buildings, but rather a combined approach of energy-efficient and low-carbon solutions, coupled with behavioural change. Other studies suggested similar strategies (Ochieng et al., n.d.; Sullivan and Gouldson, n.d.; Thompson, 2007). Green store concepts in association with sustainability assessment certification systems are fundamental to disseminate sustainable best practice in retail buildings, namely by integrating demanding energy standards (such as the Passive House standard) or by conducting life-cycle cost (LCC) and life-cycle assessments (LCA) of alternative solutions.

Building challenges that lay ahead for the retail sector are linked to the development of energy storage systems for the on-site production of renewable energy or, in alternative, the deployment of smart grids to distribute the energy surplus from variable renewable energy sources. Despite progressive decrease in energy intensities, retailers are challenged about reducing total GHG emissions mainly due to sales footprint growth. Retailers have been paving the way for energy reduction targets to be met - the disclosed information on their progress reports shows effort and evidence in that direction. Other challenges include the articulation of existing stores with soft mobility principles, and the need for Environmental Product Declarations for building materials and solutions so that the LCA of different products can be properly compared.

\subsection{Trends}

With the Paris Agreement came the realization that all must participate in solving the global challenge posed by climate change in a bottom-up approach, as demonstrated by retailers' pledge adherence. In fact, environmental responsibility is not only the responsible thing to do, but it also maximizes business value. Furthermore, good environmental performance leads to improved business resilience, cost reduction across the value chain and brand differentiation, as pointed by Galvez-Martos et al. (2013). Other drivers for sustainability are related to customer demands and expectations, regulation and legislation compliance and anticipation, society's raising awareness or NGO's activism (European Commission, 2011; Lozano, 2015; Richman and Simpson, n.d.).

In terms of retail operations in stores, corporate offices, warehouses, 
distribution centres and data centres, relevant areas in terms of future development include those of energy efficiency and the shift to green power, either produced onsite by wind and solar energy (or both) or through green energy offsetting. The shift to renewable energy produced either on or off-site, in tandem with energy-efficiency and reducing energy demand, attests to the findings of Cowanet al. (2010). Indeed, the increased use of renewable energy, coupled with energy and GHG management systems, has become central to retailers' most ambitious environmental sustainability programs. Renewable energy systems have shifted to the point where they are economically competitive, paving the way towards a lower-carbon future (Kinley, 2017).

Retailers have been able to obtain consistent improvements in energy efficiency over time, and the targets being set suggest that they expect to be able to continue to gain operational efficiency; as long as energy prices remain high - and with the regulation of GHG emissions -, companies will continue to seek improving energy and carbon efficiency, as argued by Sullivan and Gouldson $(2013,2016)$. Nonetheless, there is room for substantial improvement in retailers' energy and carbon performance, being feasible to reduce energy intensity in retail stores by a factor of 3 and carbon intensity by a factor of 6 (Ferreira et al. 2018) or to reach carbon neutrality by 2020 .

To keep energy and carbon intensity low in retail stores, the use of high-performance sustainable building solutions is likely to increase. Technologies that will make a difference in the future will be those that can promote energy-efficiency and the reduction of GHG emissions, combined with passive building solutions that minimize energy demand. Electric vehicle charging stations are also likely to grow. The shift to natural refrigerants, the reduction of refrigerant emissions per $\mathrm{m}^{2}$ of sales area, or the improvement of refrigeration efficiency are other relevant topics for retailers.

Green building certification is also likely to increase in both new and existing stores, until most of retailers' property portfolio is covered by building certification schemes (Tesco, 2018b). Green building certification not only stands as a key performance indicator for environmental management but is also useful to verify whether building solutions meet environmentally sustainable criteria. In fact, with the need for new buildings to be already designed as near or zero-energy buildings in some regions (European Commission, 2011), green building certification systems are likely to become an important tool in low impact development.

In terms of supply chain, namely in transportation and logistics, fuel efficiency, low carbon transport fuels and the minimization of food waste are up surging trends, with retailers' adherence to the Global Green Freight Action Plan, which works alongside countries to reduce GHG emissions and other freight pollutants by 2025 (IKEA, 2016). Nonetheless, the fact that the transport category had the most significant decrease between the two analysed reporting periods $(-22 \%)$ suggests a lack of progress in this area. In fact, until 2025, the main driver for reducing GHG emissions in transportation is likely to remain improved fuel efficiency, with sustainable biofuels only expected to deploy in heavy-duty trucks after 2030 (European Commission, 2011).

Despite consistent reductions in retailers' energy and carbon intensities over time, a rebound effect is apparent, as the total GHG emissions of the sector are still increasing, due mainly to business growth, as hypothesised earlier by Sullivan and Gouldson (2013). While current growth is based on more stores (and sales) for each retailer, with increasing pressure on building and logistics' GHG emissions, a low-carbon future growth may imply an expansion of online shopping, an increase of local produce and more efficient, greener logistics. GHG emissions can also be reduced by eliminating food waste; the promotion of a circular economy with zero food waste is a trend advocated by many retailers, several of them participating in coalitions such as the Food Waste Reduction Alliance (Walmart, 2018) (BSR - Business for Social Responsibility, 2011).

In terms of product stewardship (product and packaging design, owned manufacturing and production), relevant topics for retailers with increase importance are certified, green or energy efficient products, the prevention of deforestation and the promotion of a sustainable, climate-smart agriculture, with no use of chemicals. These are ways of stimulating transparency and to gain greater visibility into the GHG emissions and other impacts behind products on the shelves (RILA - Retail Industry Leaders Association, 2016).

Given that the transition to a low carbon economy requires significant investment in energy-related areas, governments are seeking to implement smart financing schemes, such as preferential interest rates in the most efficient building solutions (European Commission, 2011). While most of this extra investment would be paid back over time through lower energy bills and increased productivity, markets have a tendency to discount future benefits and disregard long-term risks. This is certainly the case of many retailers, as the limited mandate time of an administrative board is usually up to four years, thus contributing to a greater preference of low-cost building solutions. In addition, as several retailers lease stores, they may not be able to reap the benefits of longterm investments, which weakens the incentive for the application of costly high-performance sustainable solutions in retail buildings. Innovative financing instruments, such as revolving funds, preferential interest rates, guarantee schemes, risk-sharing facilities and blending mechanisms are policies that can facilitate energy investments in the private sector (European Commission, 2011). Additionally, a sufficient carbon price signal and long-term predictability, as that accomplished by the Paris Agreement, is necessary to incentivize significant reductions in GHG emissions (Kolk and Pinkse, 2008) not only in retail but in other industries as well.

The Paris Agreement also signals the private sector that national policies to encourage low carbon technologies and business models must grow. Hence, incentives for investment in low carbon alternatives and GHG emissions reductions are expected to grow, namely in energy efficiency, green power, deforestation and food waste. Retailers that are proactive on these areas can benefit from those incentives through reduced costs and maintenance (RILA - Retail Industry Leaders Association, 2016).

As the retail sector converges on the need to decrease energy consumption and GHG emissions, the next step will certainly involve adapting current business practice towards closing the carbon cycle and promoting a circular economy, as suggested by a growing number of retailers (Rewe, 2015; Auchan, 2016; Costco Wholesale, 2016; CVS Health, 2016; Edeka, 2016; ITM, 2018; Lidl, 2018; Seven and I, 2016). Whatever scenario lays ahead, retailers are anticipating change, planning for a positive impact on the planet and on GHG emissions.

\subsection{Limitations}

Some of the retailers' data collected online could be outdated as not all retailers publish sustainability/CSR reports on a yearly basis. In fact, three retailers did not publish a sustainability/CSR report after the reporting period 2014-2015. Nonetheless, these retailers were not excluded from the study, as their absence of reporting did not influence the overall results obtained.

The analytical categories recorded under each variable's table (policy, strategy and energy-related building practice) was agreed upon by all authors (an architect with 12 years of work experience in retail stores, an environmental engineer expert in green building certification systems, a civil engineer specialised in sustainable construction and a civil engineer specialised in buildings' refurbishment). Nonetheless, bias can derive from the selectivity of these authors in terms of data coding.

By employing maximum variation sampling with multi-case study sampling, some limitations occur, as it is not possible to study subgroups in depth. Even if retailers' reports are third party-certified, results could be biased, specifically in terms of practice, because energyefficient measures could be only partially applied. Nevertheless, the heterogeneity of the sample and its global representatives justify the 
trends and generalizations conceptually inferred in section $\S 3$. Further studies are needed to access namely the impact of retail typology on decarbonizing choices in policy, strategy and energy-related building practice.

Retailers' reporting continues to evolve organically, adding layers of issues that reflect the expectations of stakeholders, rather than being a dependable reflex of sustainable performance. This can be explained because of different priorities according to national legal settings related to CSR reporting, or different stakeholder needs for reported information. In addition, even if urged by transparency, retailers may also fail to see the competitive advantage of extensive sustainability reporting. The consequence is that even though the retail sector may be recognized as a leader in CSR reporting (Sullivan and Gouldson, 2012), establishing comparisons within the sector remains hard. Analogous limitations regarding CSR reporting in other industries were acknowledged by Unerman and Bennett (2004). In fact, comparison difficulties are urging companies to support the inclusion of a materiality matrix in every sustainability/CSR report, with a binding minimum number of reported material issues (Corporate Register, 2013). Nevertheless, despite data limitations, retailers' reports over the period 2014-2017 share sufficient material issues for the establishment of general trends in terms of sustainability goals, targets and performance within the analysed companies. Finally, looking only at retailers' sustainability/ CSR reports and at two-year reporting period may limit the robustness of the findings, namely regarding the time retailers had to adjust their policies and preferences to post-Paris Agreement times. To increase the robustness of policy recommendations, particularly for specific study areas, questionnaires and focus group discussions are necessary in future studies, as well as an increase of the scrutinized reporting periods.

\section{Conclusions and policy implications}

By analysing the policy, strategy and energy-related building solutions of the highest revenue retailers, this study sets out to identify the measures that contribute most to decarbonizing the retail sector and to create a dynamic in line with the Paris Agreement goals. Retailers are trying to prepare for the transition to a low carbon economy, namely through energy-efficiency measures (related or not to cost savings), and anticipating policies regarding GHG emissions to further move towards carbon neutrality.

Retailers' voluntary and representative adherence to the Paris Agreement implies that a top-down political approach that addresses the mitigation dimension first is necessary to tackle climate-change, in tandem with a bottom-up response from all societal sectors.

In terms of policy, leading retailers seem to share a strong top-down board commitment towards sustainability across all business areas and an increased use of referential reporting standards. This suggests that high levels of corporate internalization of environmental management systems lead to a higher environmental performance; in turn, the contrapositive is also likely true: a lack of strong top-down broad commitment towards sustainability across all business areas will lead to a poorer environmental performance and a dependency on external drivers to achieve sustainability standards.

Strategies to decarbonize the retail sector include establishing ambitious energy goals (such becoming carbon neutral by 2030-50) and monitoring their progress, invest in more efficient logistics (with truck fleets powered by electric/alternative fuels) and greener buildings, assessed under a life-cycle perspective (passive design with energy-efficient solutions, on-site production of renewable energy and natural refrigerants).

Corporate governance plays a key part in addressing climate change, by determining internal policies, procedures and practices that rule each organization, articulating at the same time different stakeholders' needs. The increase of governance structures in retail attests to the importance of a structured answer to complex societal issues, in order for businesses to thrive. Retailers that want to keep the field in decades to come need to devote job missions in this area, with the direct support of general management, particularly in sustainability roles. Internal policies that help to decarbonize the retail sector include green procurement, sustainable sourcing or supply chain sustainability.

As for public policy, with future regulation on GHG emissions as inevitable, the more conservative retailers will need to change and these would benefit from a concise business case on beneficial lowcarbon opportunities as well as financial incentives to support transition investments. To level the playing field, future policies should also eliminate fossil fuel subsidies, regulate carbon pricing, integrate green building performance standards and facilitate the integration of renewable energy in the grid.

Our findings help policymakers understand key areas for the decarbonization of the retail sector when adapting international directives to national regulation. These findings are also of immediate interest and application to retailers, confirming that higher environmental performance is possible based on sound sustainability policies and strategies, in turn attaining a more resilient, sustainable business. In addition, these findings can support decision-makers in defining sector policies and strategies aiming at a more ambitious environmental performance and designers (architects, engineers and others) in the choice of sustainable energy solutions for the operation of new or refurbished retail stores, in the quest for low carbon or carbon neutral buildings.

\section{Interests statement}

Declaration of interest

None. 


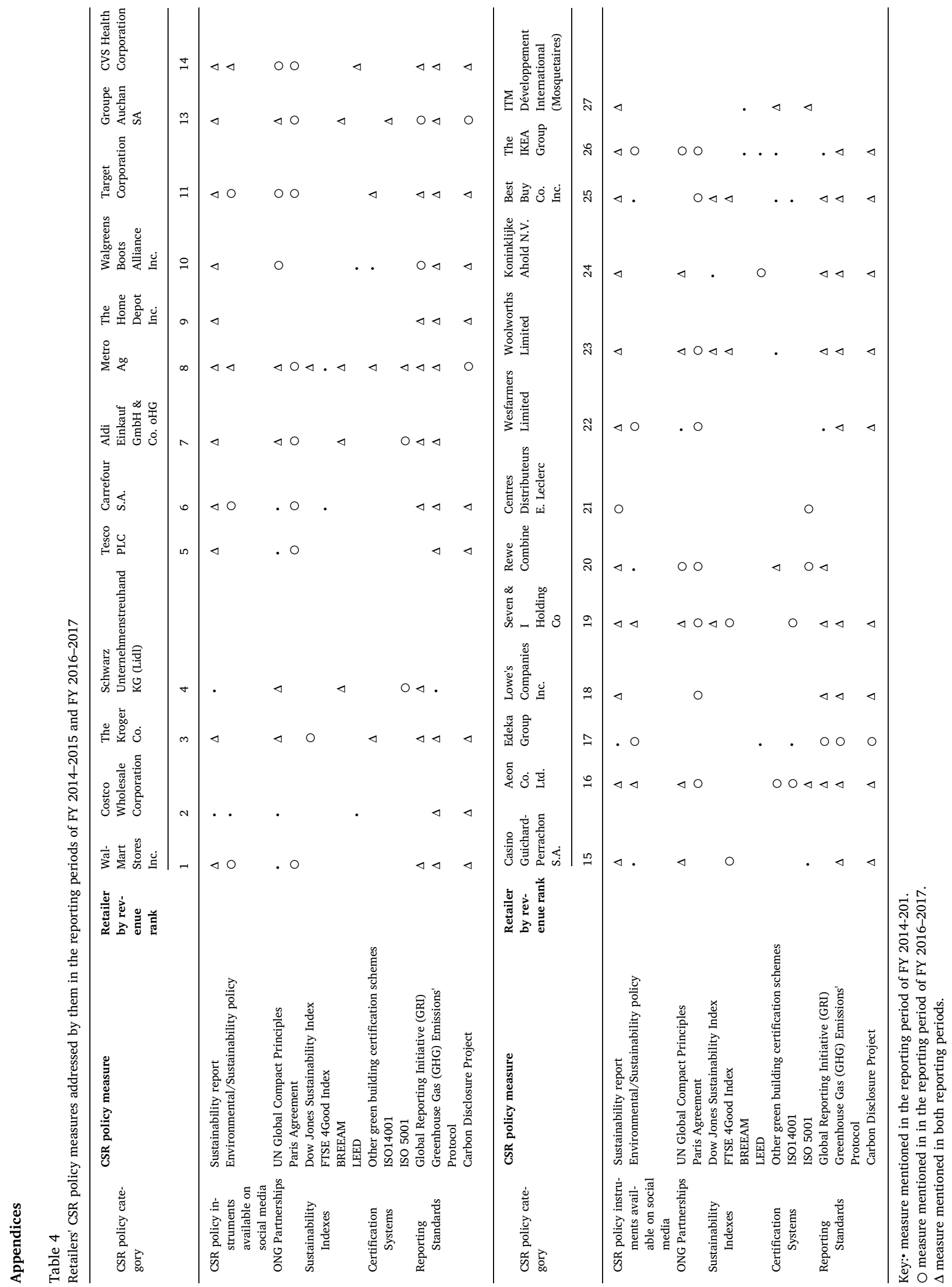




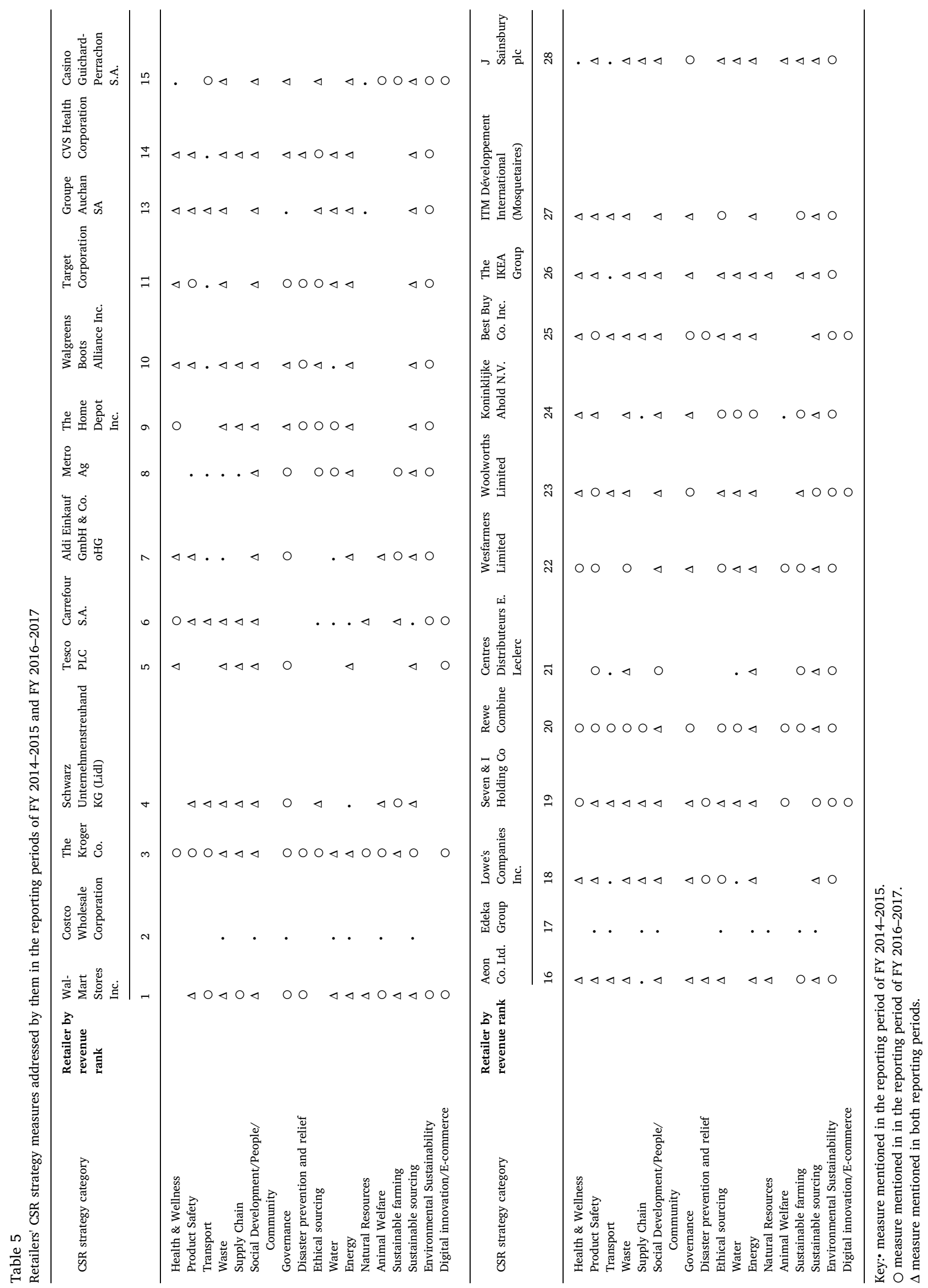




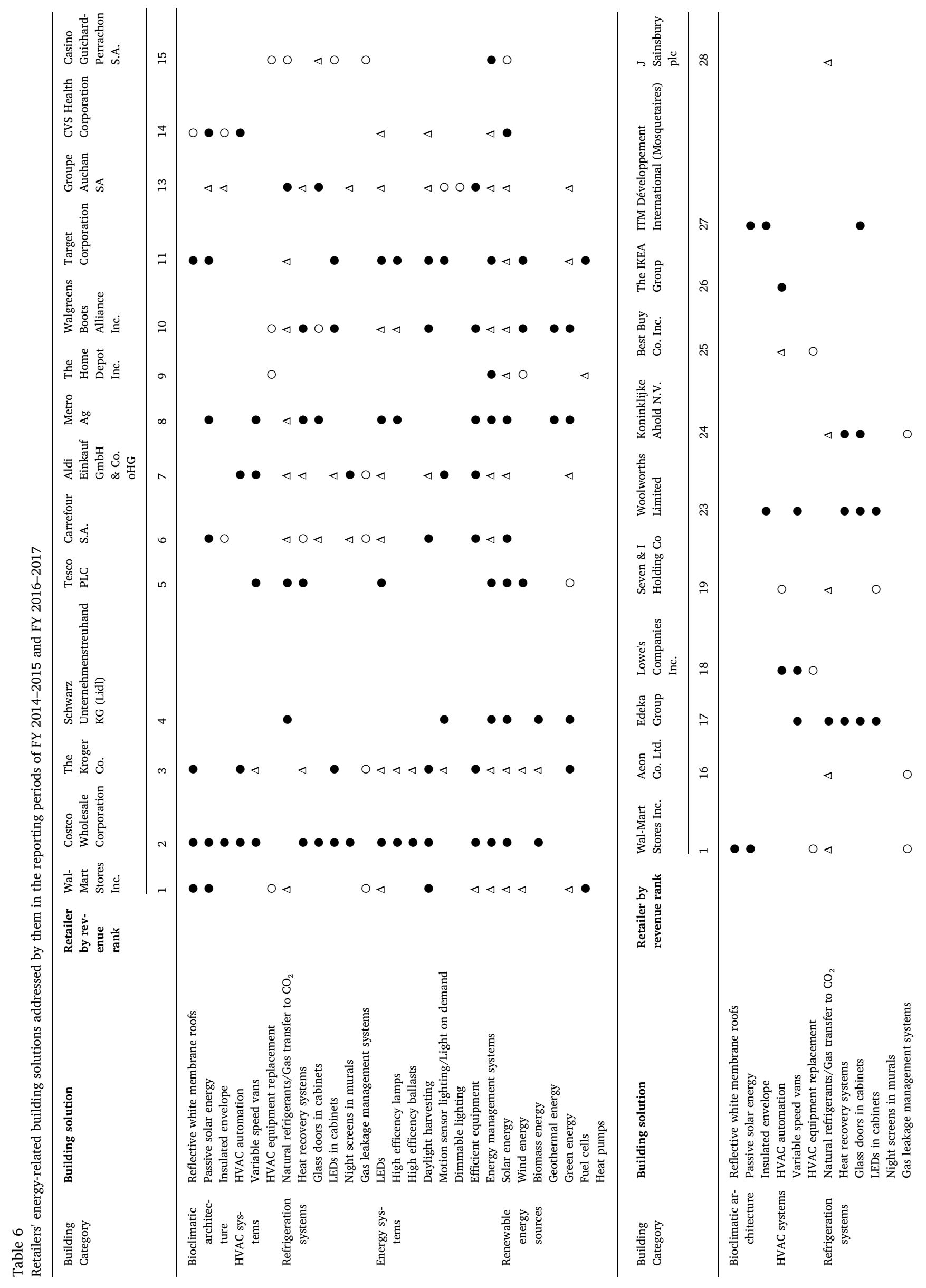




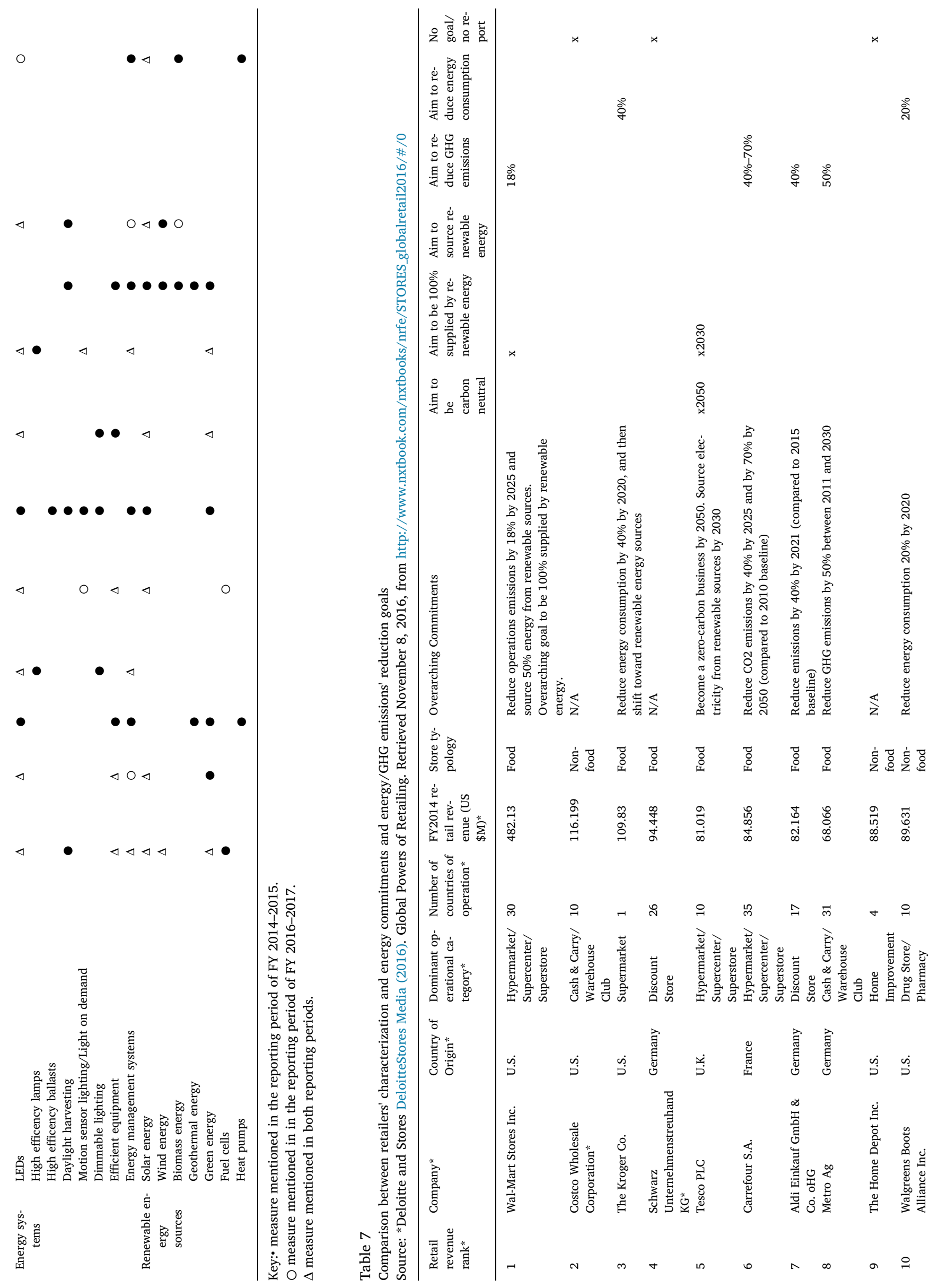


高高 音

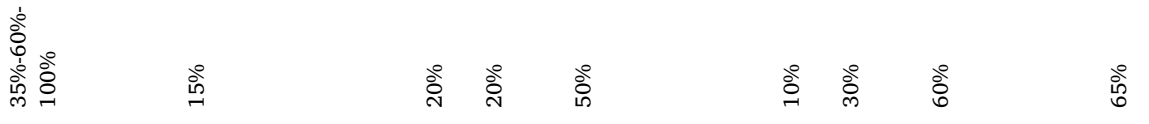

带

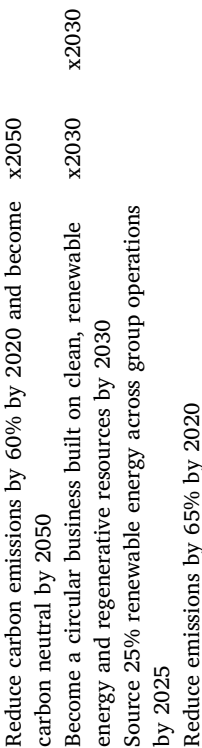

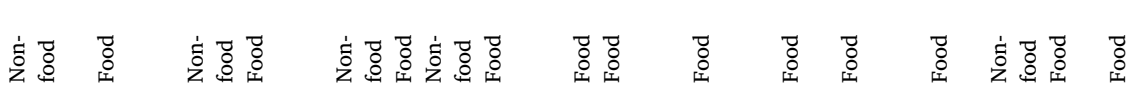

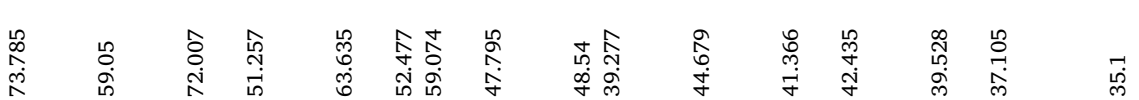

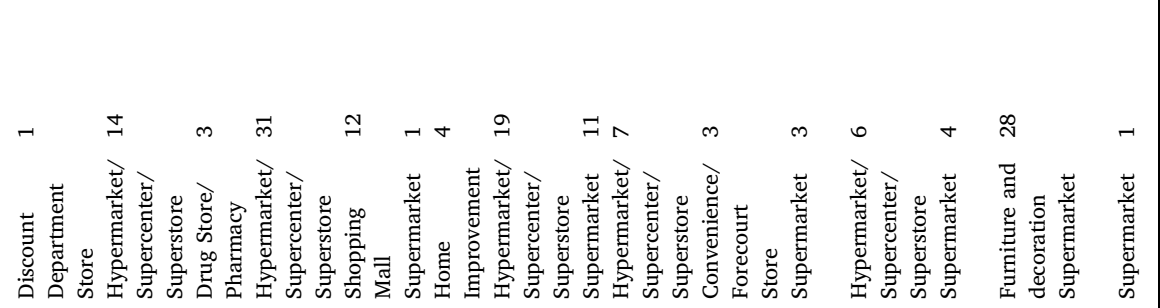

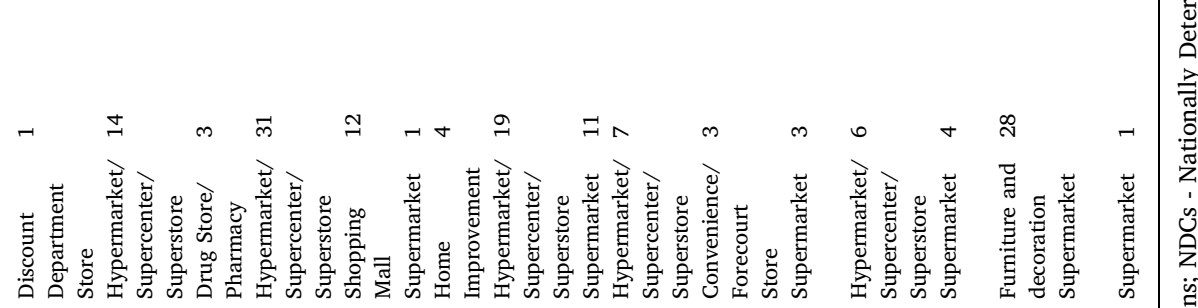

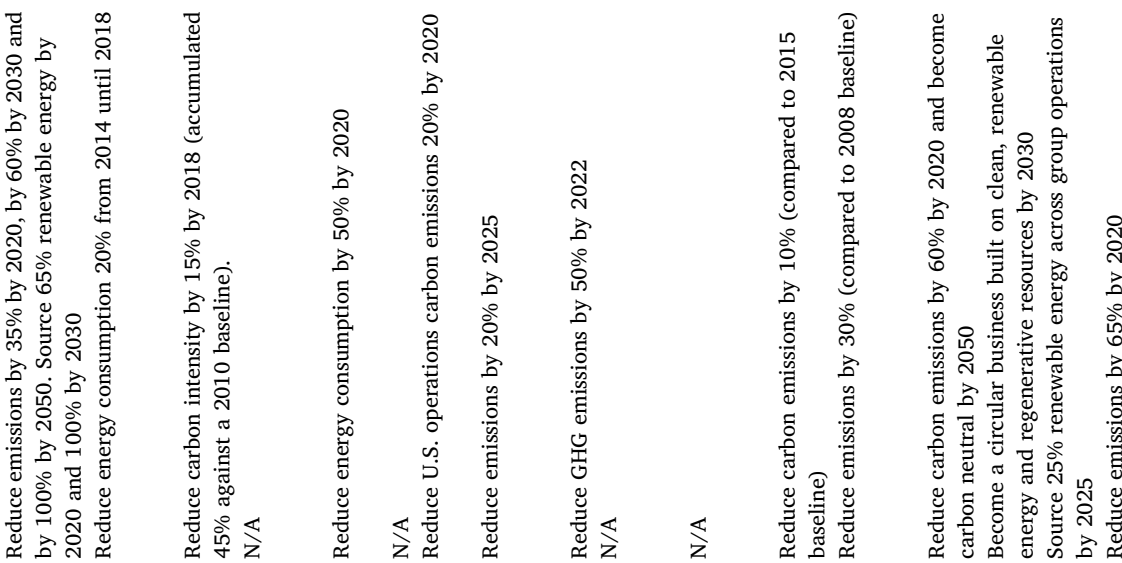

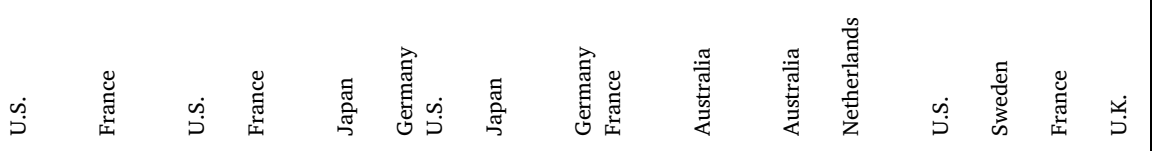

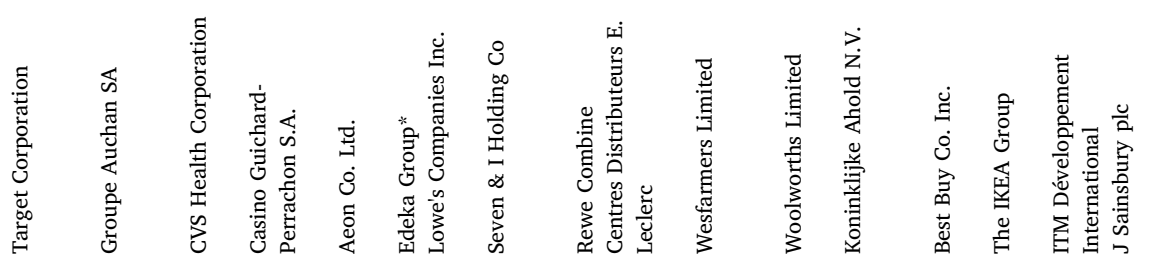

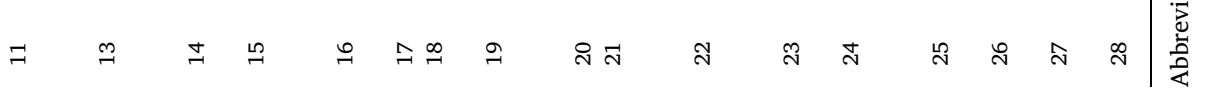




\section{Funding}

This work was supported by FCT - Fundação para a Ciência e Tecnologia [grant number PD/BD/127852/2016] under the Doctoral Program EcoCoRe - Eco-Construction and Rehabilitation. Support from CERIS and Instituto Superior Técnico is also acknowledged.

\section{References}

Aeon, 2015. Aeon environmental and social report. [Online]. Available: https://www. unglobalcompact.org/system/attachments/cop_2015/189821/original/AEON_ Environmental_and_Social_Report.pdf?1442556777, Accessed date: 21 October 2016.

Aeon, 2017. Aeon report 2017. [Online]. Available: https://www.aeon.info/export/ sites/default/common/images/en/environment/report/e_2017pdf/17_data_en_a4-2. pdf, Accessed date: 19 October 2018

Al-Tuwaijri, S.A., Christensen, T.E., Hughes, K., Jul. 2004. "The relations among environmental disclosure, environmental performance, and economic performance: a simultaneous equations approach. Account. Org. Soc. 29 (5-6), 447-471.

Aldi, 2015. Aldi North Group Sustainability Report.

Aldi, 2017. Sustainability report - simply important. [Online]. Available: https://www. sustainabilityreports.be/sites/default/files/reports/aldi_north_group_sustainability report 2017 en.pdf, Accessed date: 19 October 2018.

Auchan, 2015. Auchan activity and sustainable development report 2015. [Online]. Available: http://asp.zone-secure.net/v2/index.jsp?id=198/2213/64199\&lng =en, Accessed date: 11 November 2016.

Auchan, 2017. CSR section of the 2017 management report. [Online]. Available: https:// www.auchan-holding.com/uploads/files/modules/downloads/1523966047. 5ad5e05fc442b.pdf, Accessed date: 19 October 2018.

Baker, C.R., Cohanier, B., Pederzoli, D., 2012. Corporate social and environmental reporting in the large retail distribution sector. Procedia Econ. Financ. 2, 209-218.

Beckers, A., 2019. Towards a regulatory private law approach for CSR self-regulation? The effect of private law on corporate CSR strategies. Eur. Rev. Priv. Law 27 (2), 221-243.

Berthelot, S., Coulmont, M., Serret, V., 2012. Do investors value sustainability reports? A Canadian study. Corp. Soc. Responsib. Environ. Manag. 19 (6), 355-363.

Best Buy, 2015. Best Buy corporate responsibility and sustainability. [Online]. Available: https://corporate.bestbuy.com/sustainability/, Accessed date: 21 November 2016.

Best Buy, 2018. Corporate responsability and sustainability report. [Online]. Available: https://corporate.bestbuy.com/wp-content/uploads/2018/06/FY18-full-reportFINAL.pdf, Accessed date: 19 October 2018

Bluebeam, 2016. Walgreens walks the walk toward a net zero bottom line. [Online]. Available: http://www.bluebeam.com/us/insider/issues/1411/1411-03.asp, Accessed date: 30 November 2016.

BSR - Business for Social Responsibility, 2011. Analysis of U.S. Food Waste Among Food Manufacturers, Retailers, and Restaurants.

Bălan, C., 2010. Carbon-footprint policy of the top ten global retailers: contribution to sustainable development. AMFITEATRU Econ. J. 12, 52-65.

Carballo-Penela, A., Castromán-Diz, J.L., 2015. Environmental policies for sustainable development: an analysis of the drivers of proactive environmental strategies in the service sector. Bus. Strateg. Environ. 24 (8), 802-818.

Carrefour, 2015. Carrefour sustainability report. [Online]. Available: http://www carrefour.com/sites/default/files/carrefour_-_2015_annual_activity_and_responsible_ commitment report.pdf, Accessed date: 2 November 2016.

Carrefour, 2017. Becoming the Leader in the Food Transition for All. [Online]. Available: http://www.carrefour.com/sites/default/files/carrefour_-_2017_annual_report.pdf, Accessed date: 19 October 2018.

Casino, 2014. Casino corporate social responsibility report. [Online]. Available: https:// www.groupe-casino.fr/en/wp-content/uploads/sites/2/2015/05/Annual-ReportGroupe-Casino-2014_EN.pdf, Accessed date: 21 October 2016.

Casino, 2017. 2017 annual and corporate social responsibility performance report. [Online]. Available: https://www.groupe-casino.fr/wp-content/uploads/2018/05/ 2017-Annual-and-Corporate-Social-Responsibility-Performance-Report.pdf, Accessed date: 19 October 2018.

Christina, S., Waterson, P., Dainty, A., Daniels, K., Mar. 2015. A socio-technical approach to improving retail energy efficiency behaviours. Appl. Ergon. 47, 324-335.

Clarkson, P.M., Overell, M.B., Chapple, L., 2011. Environmental reporting and its relation to corporate environmental performance. Abacus 47 (1), 27-60.

CommONEnergy Project, 2013a. Re-conceptualize Shopping Malls from Consumerism to Energy Conservation - Deliverable 6.5 IEQ Results European Commission DC Research and Innovation CommONEnergy Re-conceptualize Shopping Malls from Consumerism to Energy Conservation. Bolzano, Italy.

CommONEnergy Project, 2013b. Re-conceptualize Shopping Malls from Consumerism to Energy Conservation - Deliverable 6.4 Energy Savings Result. Bolzano, Italy.

Corporate Register, 2013. CRPerspectives 2013. London.

Costco Wholesale, 2014. "Costco sustainability report 2014," Costco sustainability report. [Online]. Available: https://www.google.pt/?gfe_rd = cr\&ei $=$ 9ygKWLX4BJDY8gejpbgY\#q = cotsco + sustainability + report + 2014, Accessed date: 21 November 2016.

Cowan, D.M., et al., Dec. 2010. A cross-sectional analysis of reported corporate environmental sustainability practices. Regul. Toxicol. Pharmacol. 58 (3), 524-538.

CVS Health, 2015. Corporate social responsibility report | CVS health. [Online]. Available: https://www.cvshealth.com/social-responsibility/corporate-socialresponsibility/annual-corporate-social-responsibility-reports, Accessed date: 21 November 2016.
CVS Health, 2017. Corporate social responsibility report appendix. [Online]. Available: https://cvshealth.com/sites/default/files/2017-csr-report-appendix.pdf, Accessed date: 19 October 2018

Davis, K., 1960. Can business afford to ignore social responsibilities? Calif. Manag. Rev. 2 (3), 70-76.

Deloitte, 2018. Retail trends 2018. [Online]. Available: https://www2.deloitte.com/uk/ en/pages/consumer-business/articles/retail-trends.html, Accessed date: 3 December 2018.

Deloitte, Stores Media, 2016. Global powers of retailing. [Online]. Available: https:// www2.deloitte.com/content/dam/Deloitte/global/Documents/consumer-industrialproducts/gx-cip-2017-global-powers-of-retailing.pdf, Accessed date: 8 November 2016.

Dixon-O'Mara, C., Ryan, L., 2018. Energy efficiency in the food retail sector: barriers, drivers and acceptable policies. Energy Effic. 11 (2), 445-464.

Donaldson, T., Dunfee, T.W., 1994. Toward a unified conception of business ethics: integrative social contracts theory. Acad. Manag. Rev. 19 (2), 252-284.

Dupuis, J., Schweizer, R., 2019. Climate pushers or symbolic leaders? The limits to corporate climate leadership by food retailers. Environ. Pol. 28 (1), 64-86.

Dye, R.A., 1985. Disclosure of nonproprietary information. J. Account. Res. 23 (1), 123-145.

Edeka, 2015. Edeka progress report. [Online]. Available: http://www.edeka-verbund.de/ Unternehmen/media/edeka_gruppe/verantwortung/partnerschaft_wwf/ partnerschaft_wwf_1/Fortschrittsbericht_2015_english.pdf, Accessed date: 21 October 2016

Elkington, J., 1994. Towards the sustainable corporation: win-win-win business strategies for sustainable development. Calif. Manag. Rev. 36 (2).

ENDS Carbon - University of Edinburgh Business School, 2009. UK Supermarkets 2009 Carbon Benchmark Report. Edinburgh.

European Commission, 2011. A Roadmap for Moving to a Competitive Low Carbon Economy in 2050.

European Parliament, 2010. Energy performance of buildings directive. [Online]. Available: http://eur-lex.europa.eu/legal-content/EN/ALL/?uri = CELEX \%3A32010L0031, Accessed date: 30 January 2017.

European Parliament, 2018. Directive (EU) 2018/2002 on energy efficiency. [Online]. Available: https://eur-lex.europa.eu/legal-content/EN/TXT/PDF/?uri= CELEX:32018L2002\&from=EN, Accessed date: 3 May 2019.

European Parliament, European Council, 2014. Regulation (EU) No 517/2014 of 16 April 2014 on fluorinated greenhouse gases and repealing Regulation (EC) No 842/2006. [Online]. Available: https://eur-lex.europa.eu/legal-content/EN/TXT/PDF/?uri= CELEX:32014R0517\&from $=\mathrm{EN}$, Accessed date: 6 May 2019

Fenwick, M., McCahery, J.A., Vermeulen, E.P.M., Mar. 2019. The end of "Corporate' governance: hello "Platform' governance. Eur. Bus. Organ. Law Rev. 20 (1) 171-199 SI.

Ferreira, A., Pinheiro, M.D., de Brito, J., Mateus, R., 2018b. Combined carbon and energy intensity benchmarks for sustainable retail stores. Energy 165.

Galvez-Martos, J.-L., Styles, D., Schoenberger, H., Dec. 2013. Identified best environmental management practices to improve the energy performance of the retail trade sector in Europe. Energy Policy 63, 982-994.

Garriga, E., Melé, D., 2013. Corporate social responsibility theories: mapping the territory. In: Citation Classics from the Journal of Business Ethics. Celebrating the First Thirty Years of Publication, pp. 69-96.

Giannarakis, G., Konteos, G., Sariannidis, N., Chaitidis, G., 2017. The relation between voluntary carbon disclosure and environmental performance the case of S\&P 500. Int. J. LAW Manag. 59 (6), 784-803.

Gliedt, T., Hoicka, C.E., Jun. 2015. Energy upgrades as financial or strategic investment? Energy Star property owners and managers improving building energy performance. Appl. Energy 147, 430-443.

Hahn, R., Luelfs, R., 2014. Legitimizing negative aspects in GRI-oriented sustainability reporting: a qualitative analysis of corporate disclosure strategies. J. Bus. Ethics 123 (3), 401-420.

Hart, S.L., 1995. A natural-resource-based view of the firm. Acad. Manag. Rev. 20 (4), 986-1014.

Home Depot, 2015. The home Depot sustainability report. [Online]. Available: https:// corporate.homedepot.com/sites/default/files/THD_0039_2015_Sustainability_ Report Online Nov 10.pdf, Accessed date: 21 October 2016.

Hsu, A., et al., 2016. Taking Stock of Global Climate Action.

IKEA, 2016. Sustainability Report FY16.

IKEA, 2018. Sustainable strategy - people and planet positive. [Online]. Available: https://www.ikea.com/ms/en_US/pdf/people_planet_positive/IKEA_Sustainability Strategy_People_Planet_Positive_v3.pdf, Accessed date: 19 October 2018.

ITM, 2017. Rapport développment durable - les mousquetaires. [Online]. Available: http://presse.mousquetaires.com/wp-content/uploads/2017/11/rapportdeveloppement-durable-mousquetaires-2017.pdf, Accessed date: 19 October 2018

Jackson, G., Apostolakou, A., Jul. 2010. Corporate social responsibility in western Europe: an institutional mirror or substitute? J. Bus. Ethics 94 (3), 371-394.

Jenkins, D.P., 2008. Using dynamic simulation to quantify the effect of carbon-saving measures for a UK supermarket. J. Build. Perform. Simul. 1 (4), 275-288.

Ji, J., Zhang, Z., Yang, L., Jan. 2017. "Carbon emission reduction decisions in the retail-/ 
dual-channel supply chain with consumers' preference. J. Clean. Prod. 141, 852-867. Keay, A., Iqbal, T., 2018. Sustainability in large UK listed retail companies: a sectoral analysis. Deakin Law Rev. 23 (SI), 209-244.

Kim, E.-H., Lyon, T.P., 2015. Greenwash vs. Brownwash: exaggeration and undue mod esty in corporate sustainability disclosure. Organ. Sci. 26 (3), 705-723.

Kinley, R., Jan. 2017. Climate change after Paris: from turning point to transformation. Clim. Policy 17 (1), 9-15.

Kolk, A., Pinkse, J., 2008. The influence of climate change regulation on corporate responses: the case of emissions trading. In: Corporate Responses to Climate Change. Greenleaf Publishing in association with GSE Research, Sheffield, pp. 43-57.

Koninklijke Ahold, 2015. Ahold Annual Report 2015. [Online]. Available: https://www. aholddelhaize.com/media/1370/ahold_ar15_fullreport_interactive.pdf, Accessed date: 11 November 2016.

Koninklijke Ahold, 2016. Supplementary Report on Sustainable Retailing Performance 2016 Together Better.

Kroger, 2016. Kroger sustainability report. [Online]. Available: http://sustainability. kroger.com/, Accessed date: 11 November 2016.

Kroger, 2018. 2018 Sustainability report. [Online]. Available: http://sustainability. kroger.com/Kroger_CSR2018.pdf, Accessed date: 18 October 2018.

Leclerc, E., 2016. Le mouvement E.Leclerc. [Online]. Available: http://www. mouvement-leclerc.com/page/des-implantations-durables-de-magasins, Accessed date: 2 December 2016.

Levin, K., Rich, D., 2017. Turning Point: Trends in Countries' Reaching Peak Greenhouse Gas Emissions over Time. Washington DC.

Lidl, 2015. Rapports de durabilité. [Online]. Available: https://www enrouteversdemain-lidl.be/introduction/rapports-de-durabilite/?_ga $=2.152622129$ 923055288.1536665554-1973559847.1536665554, Accessed date: 11 September 2018.

Lowes, 2015. Lowe's social responsability report. [Online]. Available: http:// responsibility.lowes.com/2016/wp-content/uploads/2016/04/lowes-2015-socialresponsibility.pdf, Accessed date: 21 October 2016.

Lowes, 2017. Our future. [Online]. Available: https://1g0r7s45brd833po5f1d5yybwpengine.netdna-ssl.com/wp-content/uploads/2018/05/Lowes_2017CRReport FramingOurFuture.pdf, Accessed date: 19 October 2018.

Lozano, R., 2015. A holistic perspective on corporate sustainability drivers. Corp. Soc. Responsib. Environ. Manag. 22 (1), 32-44.

Lukić, R., Lalic, S., Sućeska, A., Hanic, A., Bugarčić, M., 2018. Carbon dioxide emissions in retail food. Ekon. Poljopr. 65, 859-874.

Marrewijk, M., 2003. Concepts and definitions of CSR and corporate sustainability: between agency and communion. J. Bus. Ethics 44, 95-105.

Metro Group, 2014. METRO GROUP corporate responsibility report 2013/14 - welcome. [Online]. Available: http://reports.metrogroup.de/2013-2014/corporateresponsibility-report/, Accessed date: 21 November 2016.

Metro Group, 2017. METRO corporate responsibility progress report 2016/17. 2017 [Online]. Available: https://reports.metroag.de/corporate-responsibility-report/ 2016-2017/, Accessed date: 19 October 2018.

Miles, M., Huberman, A., 1994. Qualitative Data Analysis, second ed. Sage Publications, Inc, Thousand Oaks, USA.

Ochieng, E.G., Jones, N., Price, A.D.F., Ruan, X., Egbu, C., Zuofa, T., Apr. 2014. Integration of energy efficient technologies in UK supermarkets. Energy Policy 67, 388-393.

Parguel, B., Benoit-Moreau, F., Larceneux, F., 2011. "How sustainability ratings might deter 'Greenwashing': a closer look at ethical corporate communication. J. Bus. Ethics 102 (1), 15-28.

Patton, M., 2002. Qualitative Research \& Evaluation Methods, third ed. Sage Publications, Inc, Thiusand Oaks, USA.

Pulker, C.E., Trapp, G.S.A., Scott, J.A., Pollard, C.M., Nov. 2018. "Global supermarkets' corporate social responsibility commitments to public health: a content analysis. Glob. Health 14.

Reilly, A.H., Hynan, K.A., Nov. 2014. "Corporate communication, sustainability, and social media: it's not easy (really) being green. Bus. Horiz. 57 (6), 747-758.

Reinvent Decarbonisation, 2017. Most carbon-intensive sectors - European Union'S horizon 2020 research and innovation programme under grant agreement NO. 730053 [Online]. Available: https://www.reinvent-project.eu/sectors, Accessed date: 28 May 2019.

Rewe, 2015. Rewe sustainability report. [Online]. Available: http://www.rewe-group. com/en/nachhaltigkeit, Accessed date: 21 November 2016.

Rewe, 2017a. Rewe group sustainability report 2017 - GRI report. [Online]. Available: www.rewe-group-nachhaltigkeitsbericht.de/2017, Accessed date: 19 October 2018.

Richman, R., Simpson, R., 2016. Towards quantifying energy saving strategies in big-box retail stores: a case study in Ontario (Canada). Sustain. Cities Soc. 20, 61-70.

RILA-Retail Industry Leaders Association, 2016. How the new agreement on climate change will impact retail background: the Paris agreement. [Online]. Available: www.rila.org/sustainability, Accessed date: 28 May 2019.

RILA - Retail Industry Leaders Association, 2017. Retail Sustainability Management Report.

Sainsbury, J., 2014. J Sainsbury CR reports and updates. [Online]. Available: http:// www.j-sainsbury.co.uk/responsibility/cr-reports/?articles_date $=2016$ \#form_filter media, Accessed date: 21 November 2016.

Sainsbury, J., 2018. Our values make us different. [Online]. Available: https://www. about.sainsburys.co.uk/ /media/Files/S/Sainsburys/documents/making-adifference/Sustainability_Update_2018.pdf, Accessed date: 19 October 2018.

Schönberger, H., Martos, J.L.G., Styles, D., 2013. Best Environmental Management Practice in the Retail Trade Sector Learning from Frontrunners.

Sebi, C., Nadel, S., Schlomann, B., Steinbach, J., Jan. 2019. Policy strategies for achieving large long-term savings from retrofitting existing buildings. Energy Effic. 12 (1),
89-105.

Seven, I, 2015. Seven \& i holdings Co CSR. [Online]. Available. https://www.7andi.com/ en/csr/csrreport/2015.html, Accessed date: 21 November 2016.

Seven, I, 2017. CSR Report 2017. [Online]. Available: https://www.7andi.com/dbps data/_template__user__SITE_localhost/_res/en/csr/csrreport/2017/pdf/2017_all_ 01.pdf, Accessed date: 19 October 2018

Smith, W., Higgins, M., 2000. Cause-related marketing: ethics and the ecstatic. Bus. Soc. 39 (3), 304-322.

C. Streck and P. Keenlyside, "The Paris agreement: a new beginning.".

Sullivan, R., Gouldson, A., Nov. 2012. Does voluntary carbon reporting meet investors needs? J. Clean. Prod. 36, 60-67.

Sullivan, R., Gouldson, A., Sep. 2013. Ten years of corporate action on climate change: what do we have to show for it? Energy Policy 60, 733-740.

Sullivan, R., Gouldson, A., 2016. Comparing the climate change actions, targets and performance of UK and US retailers. Corp. Soc. Responsib. Environ. Manag. 23 (3), $129-139$.

Suri, H., 2011. Purposeful sampling in qualitative research synthesis. Qual. Res. J. 11 (2), 63-75.

Target, 2014. Target corporate social responsibility report. [Online]. Available: https:// corporate.target.com/media/TargetCorp/csr/pdf/2014-corporate-responsibilityreport.pdf, Accessed date: 21 October 2016.

Target, 2018. 2018 target corporate responsibility report. [Online]. Available: https:// corporate.target.com/_media/TargetCorp/csr/pdf/2018_corporate_responsibility report.pdf, Accessed date: 19 October 2018.

Tesco, 2014. Tesco and society report 2014. [Online]. Available: https://www.tescoplc. com/media/1184/tesco_and_society_review_2014.pdf\%0D, Accessed date: 21 October 2016.

Tesco, 2018a. Annual report and financial statements 2018. [Online]. Available: www. tescoplc.com/ar2018, Accessed date: 18 October 2018.

Tesco, 2018b. Our targets \& actions - little helps plan - Tesco PLC. [Online]. Available. https://www.tescoplc.com/little-helps-plan/our-targets-actions/\#section7, Accessed date: 18 October 2018

Testa, F., Iraldo, F., Daddi, T., Jan. 2017. The effectiveness of EMAS as a management tool: a key role for the internalization of environmental practices. Organ. Environ. 31 (1), 48-69.

The Conservation Foundation of Greater Toronto, 2006. Greening Retail: Engaging the Retail Sector in Sustainability: Identifying the Greening Retail Opportunity for Canadian Retailers.

Thijssens, T., Bollen, L., Hassink, H., Nov. 2016. Managing sustainability reporting: many ways to publish exemplary reports. J. Clean. Prod. 136, 86-101.

Thompson, B., 2007. Green retail: retailer strategies for surviving the sustainability storm. J. Retail Leis. Prop. 6 (4), 281-286.

Unerman, J., Bennett, M., Oct. 2004. Increased stakeholder dialogue and the internet: towards greater corporate accountability or reinforcing capitalist hegemony? Account. Org. Soc. 29 (7), 685-707.

United Nations, 1992. The Rio Declaration on Environment and Development. preamble 1992.

United Nations, 2015a. Adoption of the Paris Agreement.

United Nations, 2015c. The Concept of Sustainable Development: Definition and Defining Principles. [Online]. Available: https://sustainabledevelopment.un.org/content/ documents/5839GSDR 2015_SD_concept_definiton_rev.pdf, Accessed date: 14 June 2019.

United Nations CLimate Change, 2018. N helps fashion industry shift to low carbon | UNFCCC. U. [Online]. Available: https://unfccc.int/news/un-helps-fashionindustry-shift-to-low-carbon, Accessed date: 28 May 2019.

United Nations Environment, 2017. The Kigali Amendment to the Montreal Protocol: HFC Phase-Down.

United States Senate, 2015. American Energy Efficiency Act.

United States Senate, 2019. Renewable Electricity Standard Act.

U.S. Department of Energy, 2008. Building technologies office. [Online]. Available: http://energy.gov/eere/buildings/building-technologies-office, Accessed date: 14 November 2016.

Verrecchia, R.E., Jan. 1983. Discretionary disclosure. J. Account. Econ. 5, 179-194.

Walgreens, 2015. Corporate social responsibility report 2015 | Walgreens boots alliance. [Online]. Available: http://www.walgreensbootsalliance.com/corporate-socialresponsibility-report/, Accessed date: 21 November 2016.

Walgreens, 2017. Corporate Social Responsibility Report 2017. [Online]. Available: https://www.walgreensbootsalliance.com//content/1110/files/Walgreens-BootsAlliance_Corporate-Social-Responsibility-Report-2017.pdf, Accessed date: 19 October 2018.

Walmart, 2015. Walmart global responsability report. [Online]. Available: https://cdn. corporate.walmart.com/c0/24/2383f0674d27823dcf7083e6fbc6/2015-globalresponsibility-report.pdf, Accessed date: 21 October 2016.

Walmart, 2018. 2018 global responsability report. [Online]. Available: https:// corporate.walmart.com//2018grr/media-library/document/global-responsibilityreport-2018/_proxyDocument?id $=00000165-1$ f6b-d0cc-ab77-9febd76f0000, Accessed date: 18 October 2018.

Wartick, S.L., Cochran, P., 1985. The evolution of the corporate social performance model. Acad. Manag. Rev. 10, 758-769.

Wesfarmers, 2016. Wesfarmers sustainability report. [Online]. Available: http:// sustainability.wesfarmers.com.au/, Accessed date: 21 November 2016.

Wesfarmers, 2018. Wesfarmers sustainability report 2018. [Online]. Available: https:// sustainability.wesfarmers.com.au/media/2467/sustainability website 2018.pdf, Accessed date: 19 October 2018

Woolworths, 2015. Woolworths corporate responsibility report. [Online]. Available: http://woolworthslimited2015.csr-report.com.au/files/Woolworths CSR 2015.pdf, 
Accessed date: 21 October 2016

Woolworths, 2018. Integrated report 2018. [Online]. Available: https://www.

woolworthsholdings.co.za/wp-content/uploads/2018/09/WHL-2018-IntegratedReport.pdf, Accessed date: 19 October 2018.

Yu, Y., Jul. 2015. An empirical analysis of the relationship between environmental performance and sustainable e-governance in China. Technol. Forecast. Soc. Chang. 96, $71-78$.

\section{Further Reading}

IKEA, 2015. IKEA sustainability report. [Online]. Available: http://www.ikea.com/ms/
en_US/img/ad_content/2015_IKEA_sustainability_report.pdf, Accessed date: 21 October 2016.

Rewe, 2017b. REWE group sustainability report 2017. [Online]. Available: http://rewegroup-nachhaltigkeitsbericht.de/2017/en/gri-report/ece/gri-ece/index\#, Accessed date: 19 October 2018.

United Nations, 2015b. COP 21 Paris. noviembre 25 [Online]. Available: http://www. cop21 paris.org/about/cop21/, Accessed date: 19 October 2018.

WRI, WBCSD, 2016. Greenhouse Gas Protocol. [Online]. Available: http://www. ghgprotocol.org/, Accessed date: 8 November 2016. 